\title{
PULSED ULTRASOUND FOR BONE REGENERATION - OUTCOMES AND HURDLES IN THE CLINICAL APPLICATION: A SYSTEMATIC REVIEW
}

\author{
R. Puts ${ }^{1, *}$, L. Vico ${ }^{2}$, N. Beilfuß ${ }^{1}$, M. Shaka ${ }^{1}$, F. Padilla ${ }^{3,4}$ and K. Raum ${ }^{1}$ \\ ${ }^{1}$ Charité-Universitätsmedizin Berlin, corporate member of Freie Universität Berlin, Humboldt-Universität \\ zu Berlin, and Berlin Institute of Health, BCRT - Berlin Institute of Health Centre for Regenerative \\ Therapies, 13353 Berlin, Germany \\ ${ }^{2}$ INSERM, U1059, University of Lyon, University of Saint-Etienne, F-42270 Saint-Etienne, France \\ ${ }^{3}$ Focused Ultrasound Foundation, Charlottesville, VA 22903, USA \\ ${ }^{4}$ Department of Radiology, University of Virginia School of Medicine, Charlottesville, VA, USA
}

\begin{abstract}
Impaired bone-fracture healing is associated with long-term musculoskeletal disability, pain and psychological distress. Low-intensity pulsed ultrasound (LIPUS) is a non-invasive and side-effect-free treatment option for fresh, delayed- and non-union bone fractures, which has been used in patients since the early 1990s. Several clinical studies, however, have questioned the usefulness of the LIPUS treatment for the regeneration of long bones, including those with a compromised healing. This systematic review addresses the hurdles that the clinical application of LIPUS encounters. Low patient compliance might disguise the effects of the LIPUS therapy, as observed in several studies. Furthermore, large discrepancies in results, showing profound LIPUS effects in regeneration of small-animal bones in comparison to the clinical studies, could be caused by the suboptimal parameters of the clinical set-up. This raises the question of whether the socalled "acoustic dose" requires a thorough characterisation to reveal the mechanisms of the therapy. The adequate definition of the acoustic dose is especially important in the elderly population and patients with underlying medical conditions, where distinct biological signatures lead to a delayed regeneration. Nonindustry-funded, randomised, double-blind, placebo-controlled clinical trials of the LIPUS application alone and as an adjuvant treatment for bones with complicated healing, where consistent control of patient compliance is ensured, are required.
\end{abstract}

Keywords: Low-intensity pulsed ultrasound, bone regeneration, surgery, acoustic dose, non-union, age, osteoporosis, compliance.

*Address for correspondence: Regina Puts, Berlin Institute of Health Centre for Regenerative Therapies, Charité-Universitätsmedizin, Föhrer Straße 15, 13353 Berlin, Germany.

Telephone number: +4930450539506 Email: regina.puts@charite.de

Copyright policy: This article is distributed in accordance with Creative Commons Attribution Licence (http://creativecommons.org/licenses/by-sa/4.0/).

\begin{tabular}{llll}
\hline & List of Abbreviations & LIPUS & low-intensity pulsed ultrasound \\
& & MMP & matrix metalloproteinase \\
BMD & bone mineral density & MSC & mesenchymal stromal cell \\
BMP & bone morphogenetic protein & No & nitric oxide \\
CT & computed tomography & ORIF & pulse repetition frequency \\
DC & duty cycle & PRISMA & preferred reporting items for \\
DKK-1 & Dickkopf-1 & & systematic reviews and meta- \\
DXA & dual-energy X-ray absorptiometry & analyses \\
ECM & extracellular matrix & & randomised double-blind clinical \\
HIF-1 $\alpha$ & hypoxia-inducible factor $1 \alpha$ & RCT & trial \\
IM & intramedullary & & Runt-related transcription factor 2 \\
I $_{\text {SATA }}$ & spatial average temporal average & Runx-2 & standard deviation
\end{tabular}


TB

TMJ

TRUST

VEGF-A
Twin-Block

temporomandibular joint

trial to re-evaluate low-intensity

pulsed UltraSound in treatment of tibial fractures

vascular endothelial growth factor A

\section{Introduction}

According to the USA National Health Interview Survey, more than half of all chronic medical conditions reported in 2012 were associated with musculoskeletal problems (Hauser et al., 2016). The bone is an organ able to regenerate after a fracture to its full functional integrity without scar formation. However, approximately $10 \%$ of all fractures do not heal without complications (Volpin, 2014). These cases, also known as delayed- and non-union bone fractures, are accompanied by the life burdens of limited or no mobility, pain and psychological stress (Lerner et al., 1993; Mitchell et al., 2018). Moreover, the median total costs for treating a non-union in the USA was calculated to be USD 25,556 (Antonova et al., 2013). With progressing age, the odds of a complicated bone healing abruptly increase (Clark et al., 2017). Since the proportion of ageing population continually grows, especially in the developed countries, the advances in novel technologies for efficient fracture regeneration are especially urgent.

In 1983, Duarte showed that stimulation of osteotomised rabbit fibula and femur bones with LIPUS enhanced callus formation (Duarte, 1983). Currently, a device employing LIPUS is manufactured under the brand name of Exogen ${ }^{\circledR}$ (Bioventus LLC, Durham, NC, USA), which emits pulsed sine waves at an ultrasound frequency of $1.5 \mathrm{MHz}$, a PRF of $1 \mathrm{kHz}$ and a $20 \%$ DC, generating a $\mathrm{I}_{\mathrm{SATA}}$ of $30 \mathrm{~mW} /$ $\mathrm{cm}^{2}$ (Pounder and Harrison, 2008). Exogen ${ }^{\circledR}$ is used across the globe for the treatment of fresh fractures, delayed- and non-union bones and, so far, no negative side effects have been reported. The device is fully portable and does not require medically qualified staff for its operation. The treatment can be applied by the patient at home and lasts $20 \mathrm{~min} / \mathrm{d}$ for the prescribed period. However, the question of the efficiency and suitability of the LIPUS technique for fracture healing remains open for debate (Busse et al., 2014; Garner, 2017; Griffin, 2016; Griffin et al., 2014; Poolman et al., 2017; Schandelmaier et al., 2017a; Tarride et al., 2017; TRUST Investigators writing group et al., 2016).

Once a bone fracture occurs, the orthopaedic surgeon has to decide the suitable type of treatment for the patient, with surgery being increasingly the first choice (Courtney et al., 2011; Fernandez, 2005; Schmidt et al., 2003). Should complementary methods, such as LIPUS, be used as an adjuvant to the conservative option with cast or to surgery? Can LIPUS be beneficial for bones with complicated healing? The purpose of the present review is to provide the reader with an impartial opinion on the above questions.

\section{Materials and Methods}

Search and retrieval of scientific studies was conducted in accordance with the PRISMA (Moher et al., 2009). Studies published between December 1950 and April 2021 were collected from PubMed and Web of Science databases using as keywords "lowintensity pulsed ultrasound" and "bone fracture". Search duplicates were first identified using EndNote software. Then, these were verified and further removed manually. Articles, that were not peerreviewed, without a full-text option or written in a language other than English were excluded. Studies describing in vitro findings and studies in animal models were not retained for the main data analysis. Additionally, articles irrelevant to ultrasound, using ultrasound for other purposes than LIPUS stimulation or describing LIPUS application in other organs than bone were excluded.

\section{Results}

A PRISMA diagram describing the identification of manuscripts for the data analysis is depicted in Fig. 1. The search queries identified 449 and 357 search results using PubMed and Web of Science databases, respectively. 6 publications, meeting all the inclusion criteria, were found in a Google Scholar free search and designated in the PRISMA chart as "other sources". EndNote software identified 134 duplicates and an additional 95 were excluded upon manual verification, resulting in 583 search results. A restriction of the search results based on full-text peerreviewed articles in English language excluded 43 additional studies. LIPUS application in vitro, in silico and in animal models accounted for 88, 2 and 139 entries, respectively. These were identified following thorough screening of the full-text articles. Studies, irrelevant to ultrasound techniques (27), irrelevant to bone fracture stimulation (10) or describing other ultrasound methods (111) were screened out manually and excluded from the analysis. Finally, 163 articles met all the set criteria. Out of them, 77 and 24 were review articles and case studies (data not shown), respectively. Finally, 62 articles (Table 1-3) reporting original findings were included in the present review. Most of the clinical studies identified employ Exogen ${ }^{\circledast}$ or Exogen ${ }^{\circledR}$-like stimulation devices, with the clinical acoustic parameters of $1.5 \mathrm{MHz}$, $1 \mathrm{kHz}$ PRF, $20 \%$ DC and $30 \mathrm{~mW} / \mathrm{cm}^{2} \mathrm{I}_{\mathrm{SATA}}$. These are summarised in Table 1-3. 9 studies use LIPUS parameters that are different from the conventionally used ones or are not clearly specified (Arima et al., 2017; Bawale et al., 2020; Gan et al., 2014; Gopalan et 
al., 2020; Liu et al., 2014; Ozdemir et al., 2008; Patel et al., 2015; Santana-Rodríguez et al., 2019; Warden et al., 2001).

\section{LIPUS and fresh fractures: surgery vs. cast}

There are several hurdles that the application of LIPUS in a clinical setting encounters. The first is the definition of a fresh fracture, which discriminates cases older than 1 week (Heckman, 2017; Zura et al., 2017). This might prevent some potential candidates from receiving non-invasive treatment strategies such as LIPUS. Furthermore, a large number of studies dedicated to LIPUS stimulation of fresh fractures are either based on case studies (data not shown), retrospective studies (Akiyama et al., 2014; Arima et al., 2017; Kinami et al., 2013; Ota et al., 2018; Ota et al., 2017; Song et al., 2019; Zura et al., 2015b) or prospective trials conducted in an unblinded manner and/or without sham controls (Arimoto et al., 2019; Brand et al., 1999; Dudda et al., 2011; El-Mowafi and Mohsen, 2005; Gan et al., 2014; Gold and Wasserman, 2005; Gopalan et al., 2020; Leung et al., 2004b; Liu et al., 2014; Patel et al., 2015; Salem and Schmelz, 2014; Santana-Rodríguez et al., 2019; Tsumaki et al., 2004; Urita et al., 2013) (Table 1), challenging the credibility of the LIPUS therapy. Additionally, the small size of patient cohorts of several prospective, randomised, double-blind, placebo-controlled trials diminish the importance of their findings (Emami et al., 1999; Handolin et al., 2005a; Handolin et al., 2005b; Raza et al., 2016).

The discussion on whether LIPUS should be used as an alternative or an adjuvant therapy to surgical intervention has become more intense recently, especially since the results of the multicentre randomised, blinded, sham-controlled clinical trial TRUST was published in 2016 (Busse et al., 2014; TRUST Investigators writing group et al., 2016). The study enrolled 501 patients with tibial fractures treated surgically and fixed with an IM nail. No effect of LIPUS stimulation on the radiographically indicated healing time and restoration of full bonefunctionality was observed. The data were published soon after as a BMJ Rapid Recommendations article (Poolman et al., 2017), advising the removal of LIPUS from clinical practice. A systematic review (Schandelmaier et al., 2017a) further analysed 26 randomised trials on the use of LIPUS therapy in all types of fracture, concluding that only 3 unbiased studies (Busse et al., 2014; Emami et al., 1999; TRUST Investigators writing group et al., 2016) have been published, with two of them being the results of the TRUST study. LIPUS treatment in these studies was not found to accelerate bone healing. The high risks of bias were defined as i) the lack of a blinded expert, ii) non-identically looking sham device, iii) a

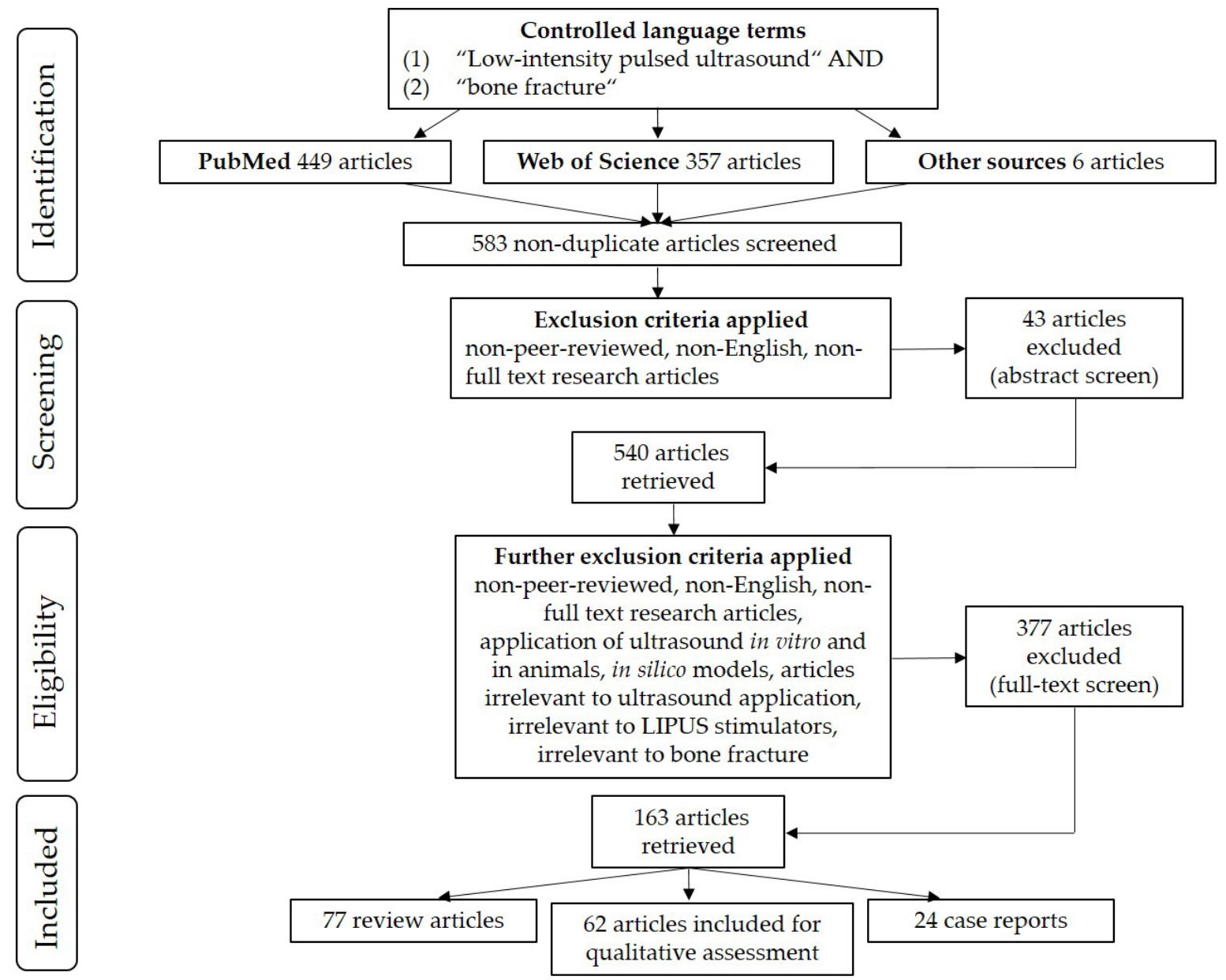

Fig. 1. PRISMA diagram of search inclusion and exclusion criteria. The search yielded 62 scientific studies published between December 1950 and April 2021 that were analysed in the present review. 


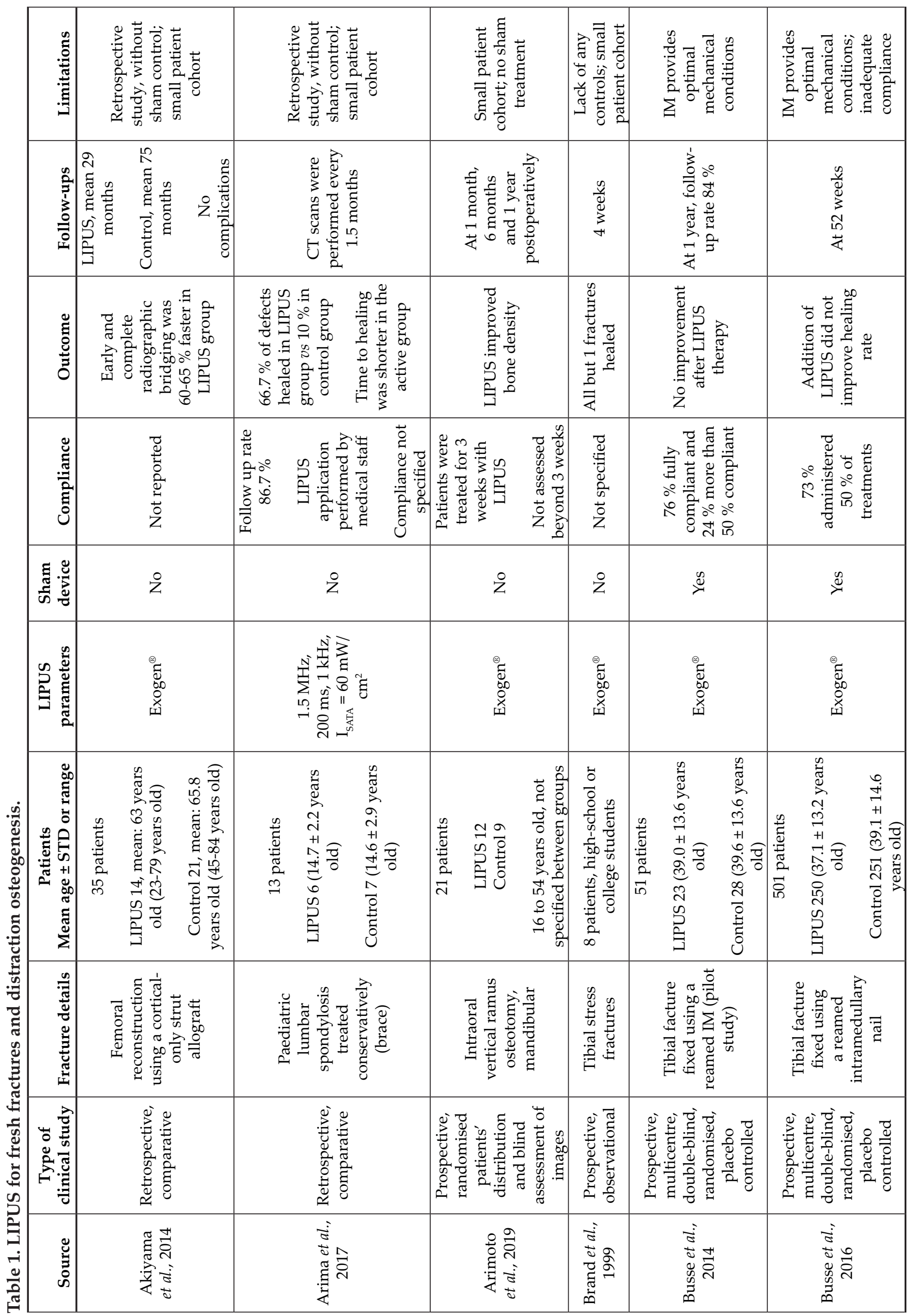




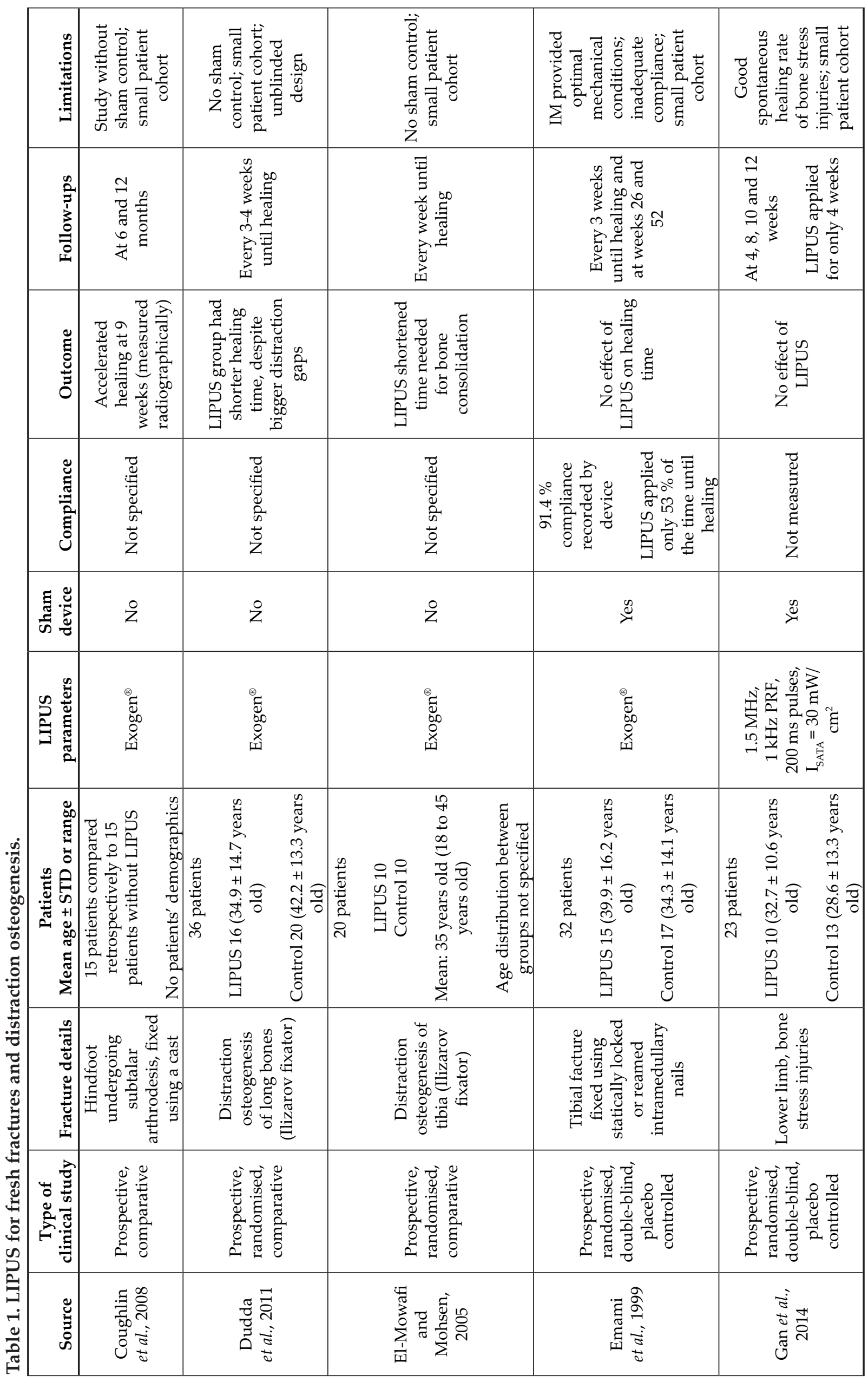




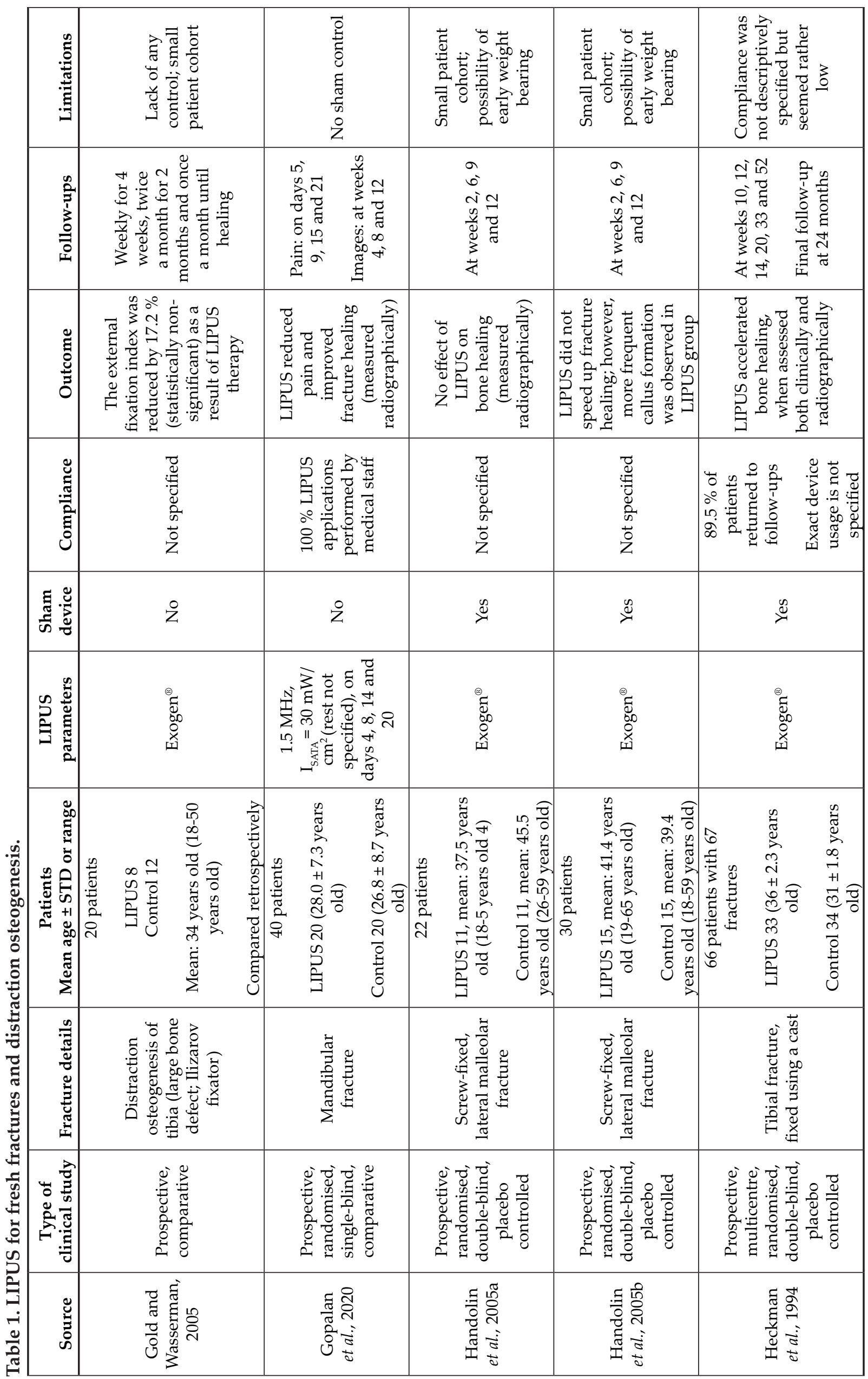




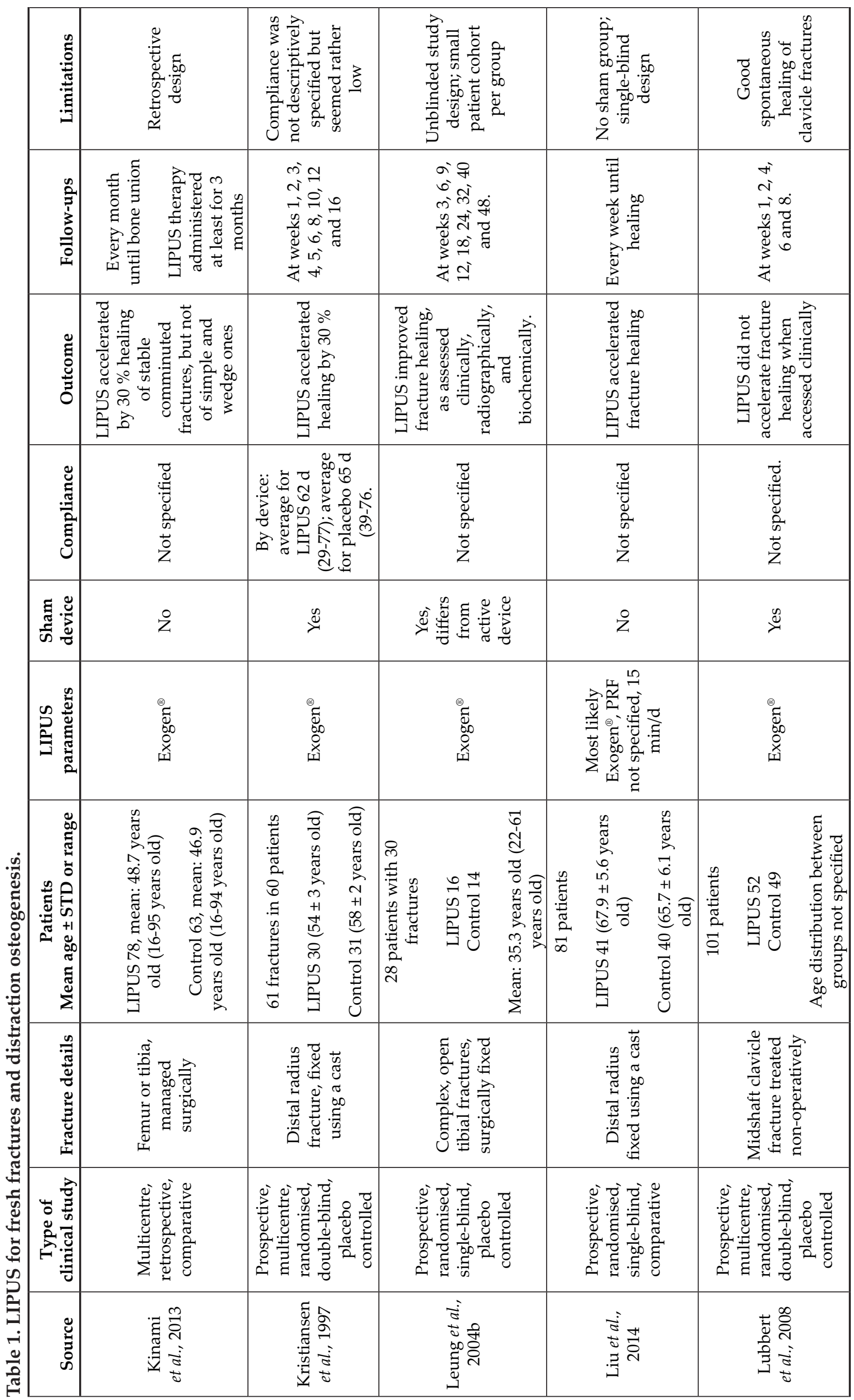




\begin{tabular}{|c|c|c|c|c|c|c|c|}
\hline & 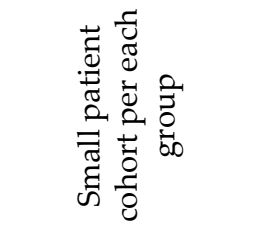 & 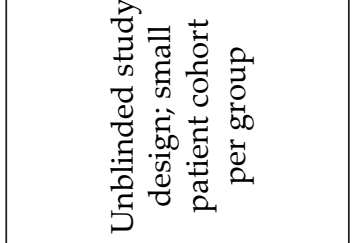 & 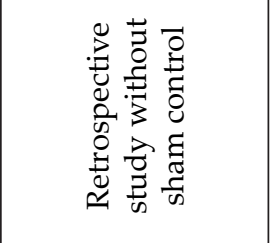 & \multicolumn{2}{|c|}{ 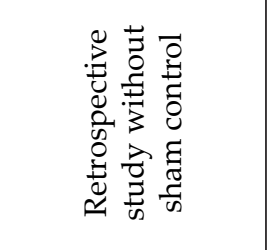 } & \multicolumn{2}{|r|}{ 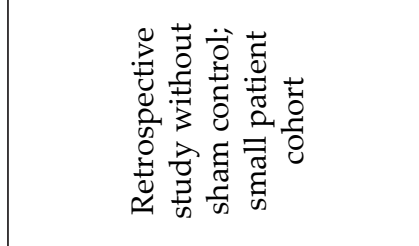 } \\
\hline & 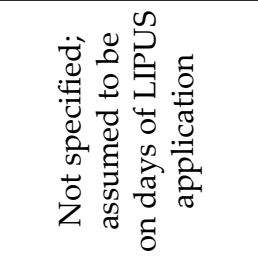 & 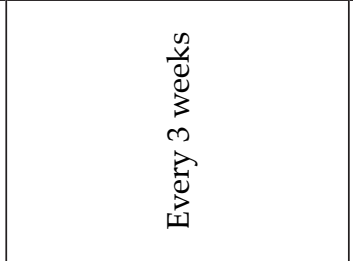 & 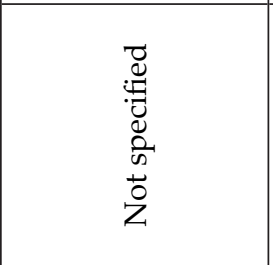 & \multicolumn{2}{|c|}{ 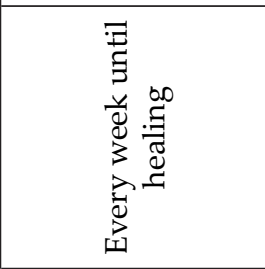 } & \multicolumn{2}{|r|}{ 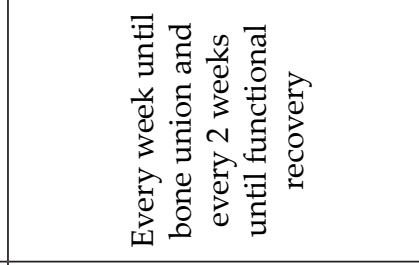 } \\
\hline & 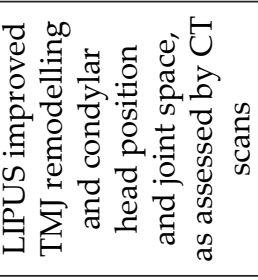 & 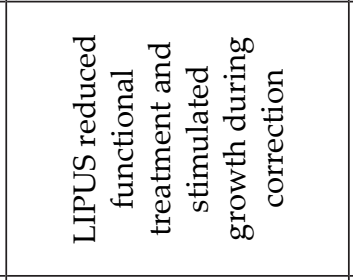 & 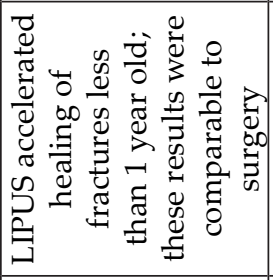 & \multicolumn{2}{|c|}{ 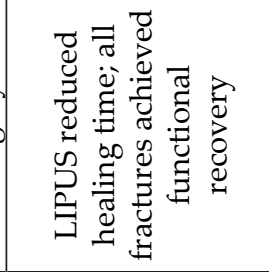 } & \multicolumn{2}{|c|}{ 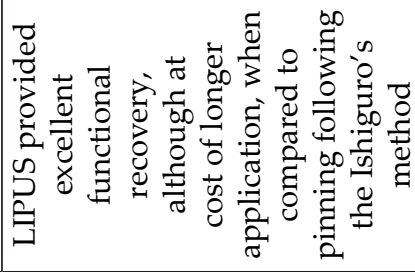 } \\
\hline & 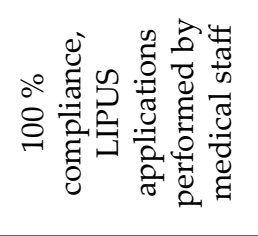 & 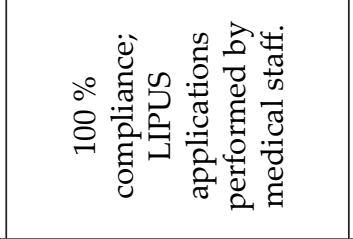 & 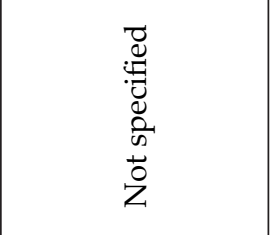 & \multicolumn{2}{|c|}{ 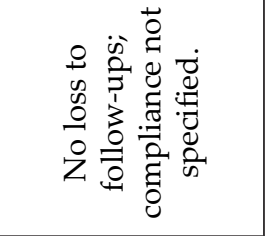 } & \multicolumn{2}{|r|}{ 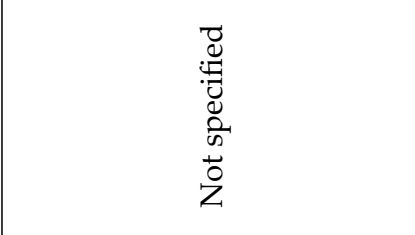 } \\
\hline & $\underset{خ}{\mathscr{C}}$ & 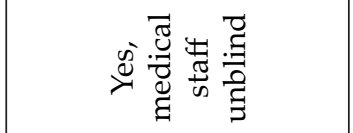 & $\stackrel{2}{z}$ & \multicolumn{2}{|l|}{ z } & \multicolumn{2}{|r|}{$\stackrel{\circ}{z}$} \\
\hline & 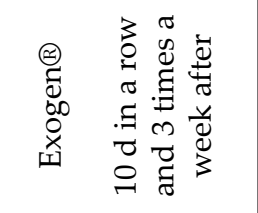 & 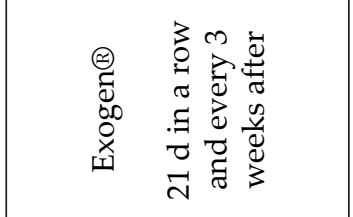 & 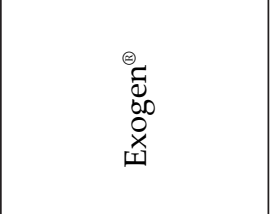 & \multicolumn{2}{|l|}{ 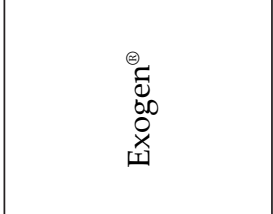 } & \multicolumn{2}{|r|}{ 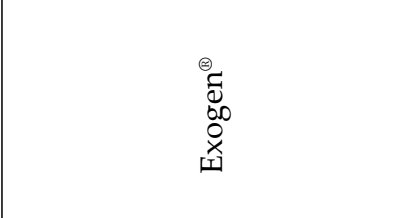 } \\
\hline & 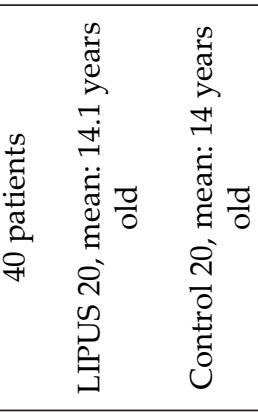 & 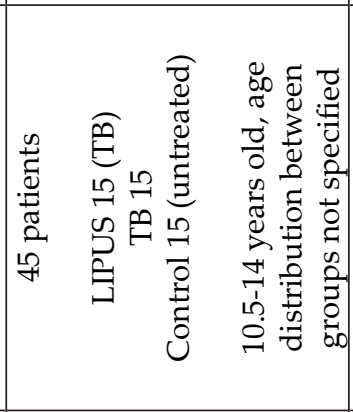 & 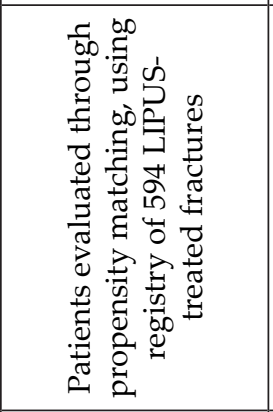 & 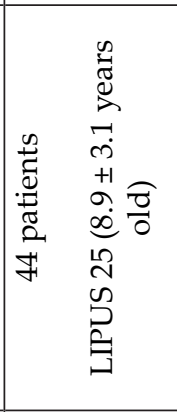 & 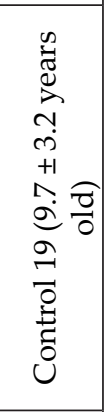 & 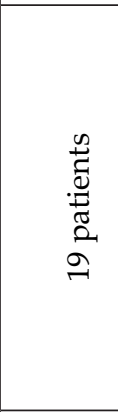 & 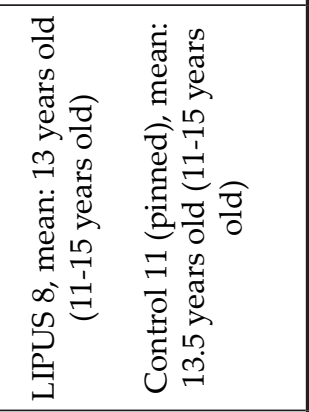 \\
\hline & 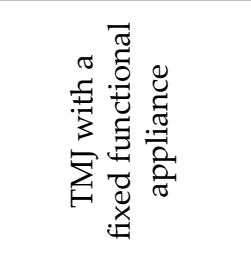 & 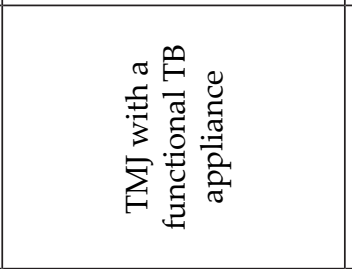 & 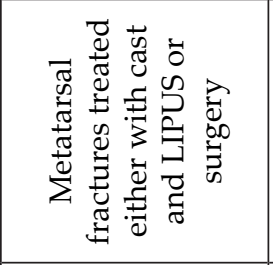 & \multicolumn{2}{|c|}{ 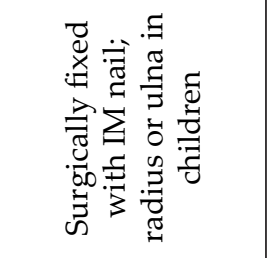 } & \multicolumn{2}{|r|}{ 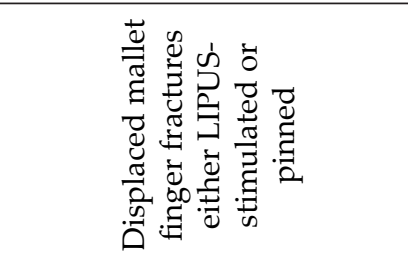 } \\
\hline & 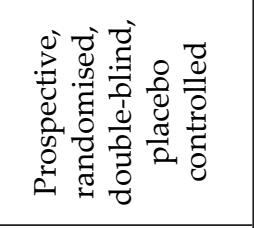 & 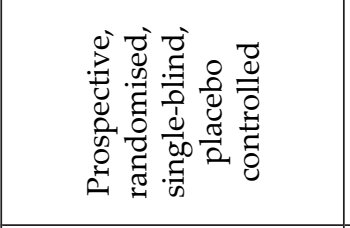 & 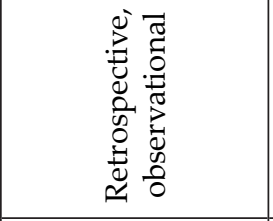 & \multicolumn{2}{|c|}{ 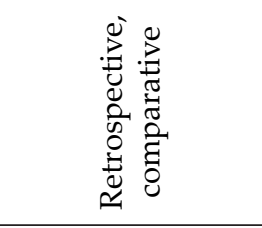 } & \multicolumn{2}{|r|}{ 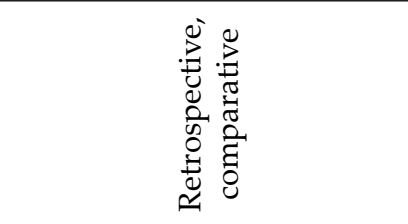 } \\
\hline & 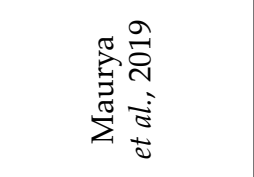 & 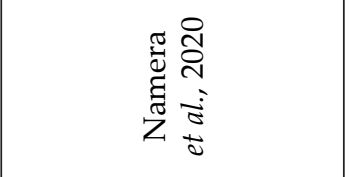 & 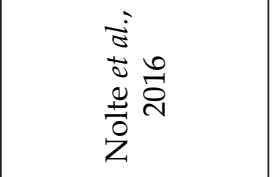 & \multicolumn{2}{|c|}{ 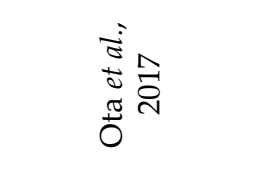 } & \multicolumn{2}{|r|}{ 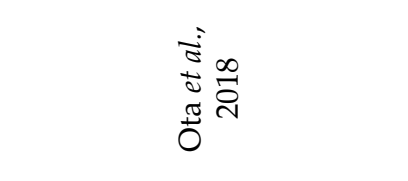 } \\
\hline
\end{tabular}




\begin{tabular}{|c|c|c|c|c|c|c|}
\hline 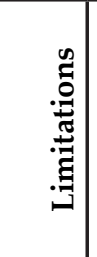 & 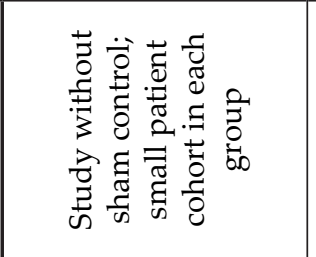 & 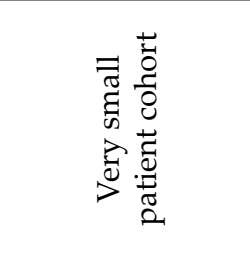 & 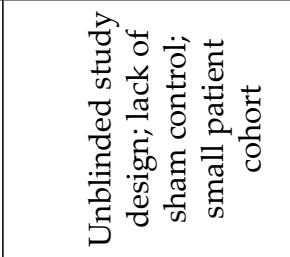 & & 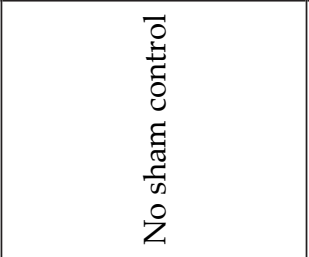 & 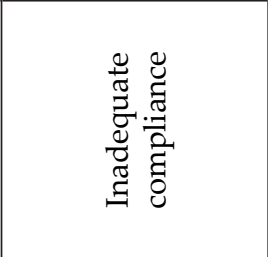 \\
\hline 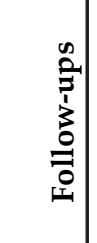 & 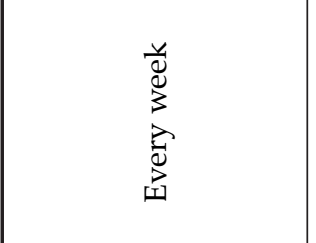 & 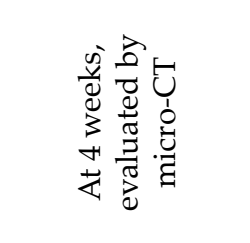 & 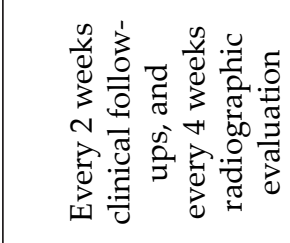 & & 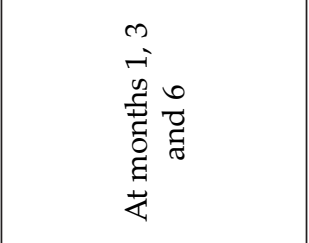 & 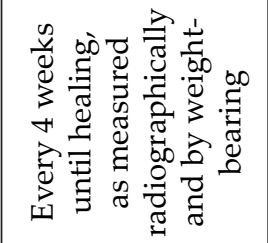 \\
\hline 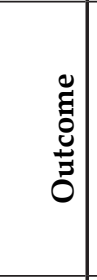 & 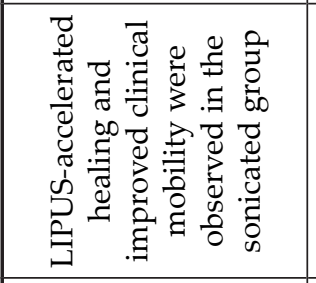 & 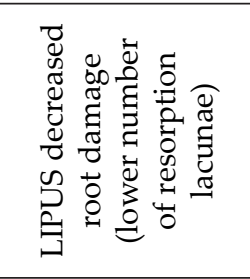 & 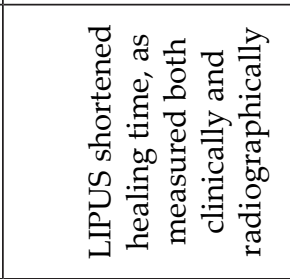 & & 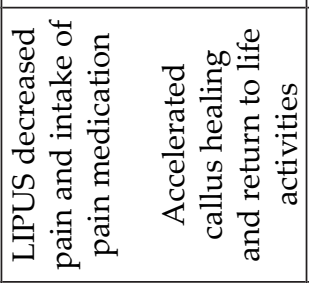 & 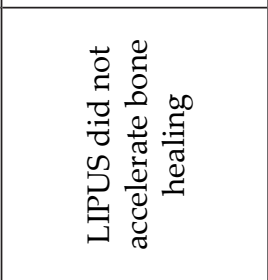 \\
\hline 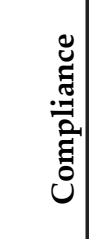 & 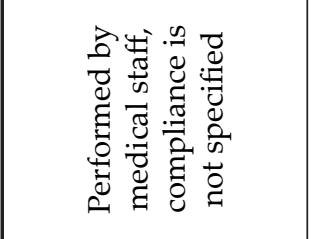 & 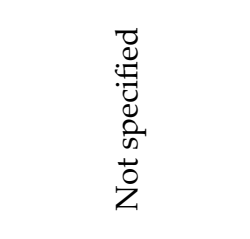 & 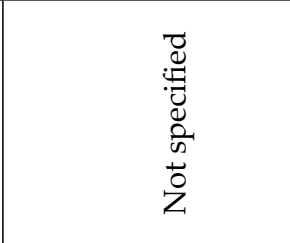 & & 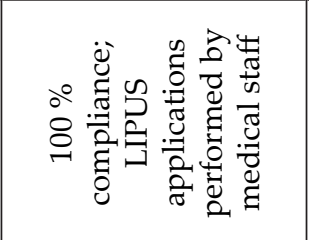 & 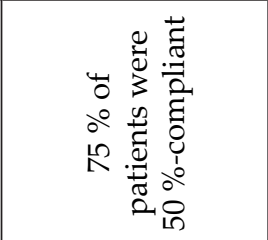 \\
\hline 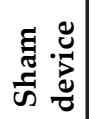 & $\stackrel{\circ}{z}$ & 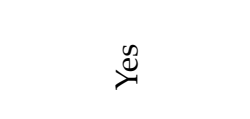 & z & & ¿̊ & 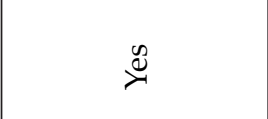 \\
\hline 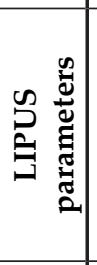 & 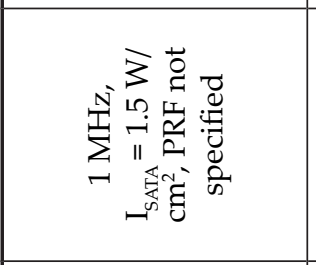 & 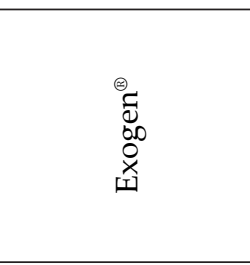 & 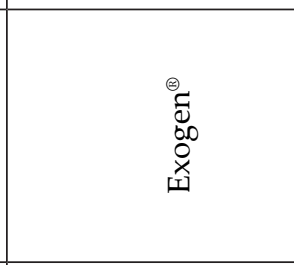 & & 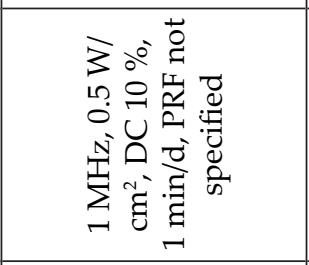 & 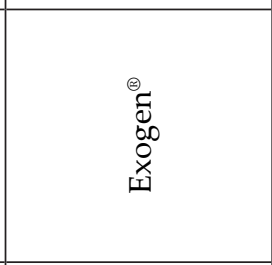 \\
\hline 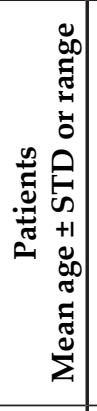 & 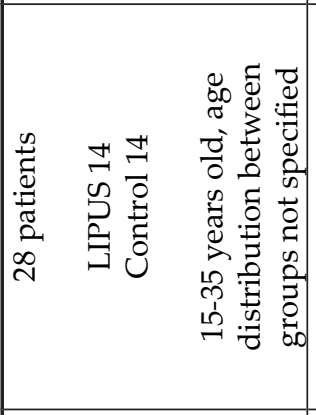 & 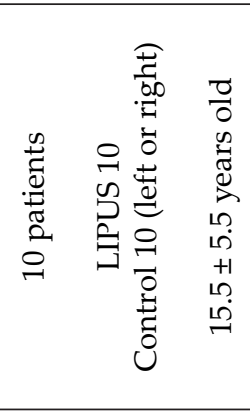 & 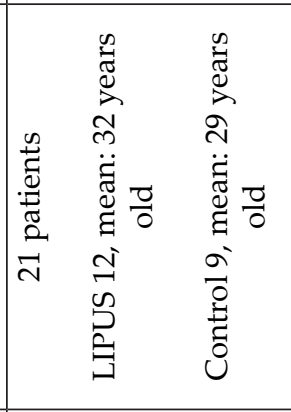 & 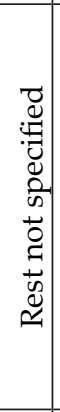 & 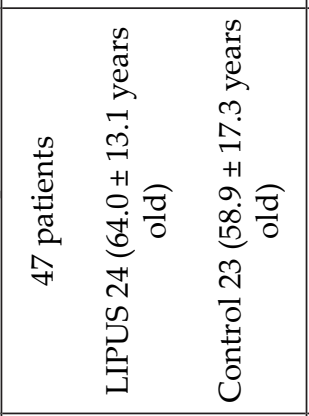 & 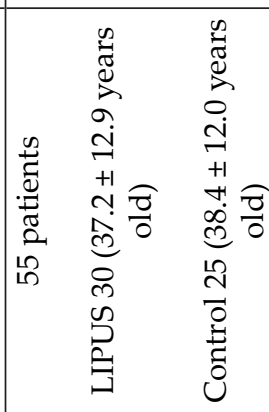 \\
\hline 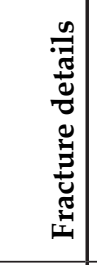 & 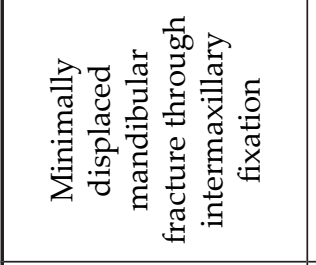 & 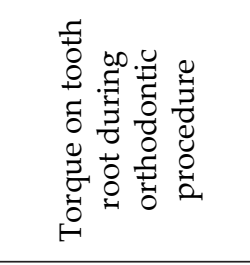 & 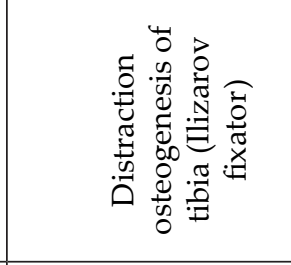 & & 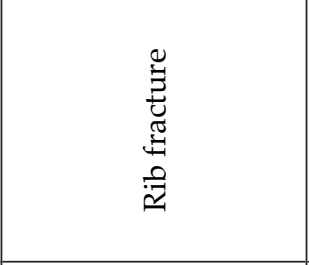 & 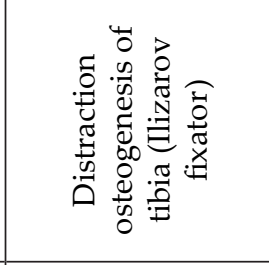 \\
\hline 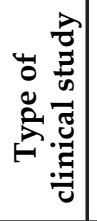 & 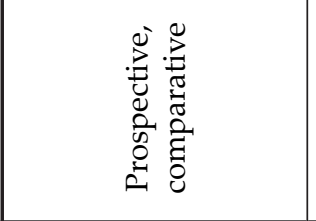 & 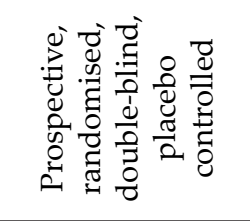 & 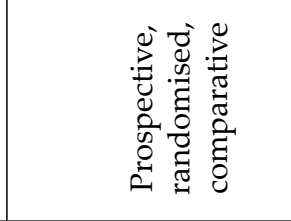 & & 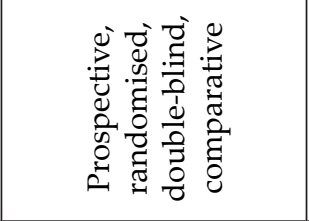 & 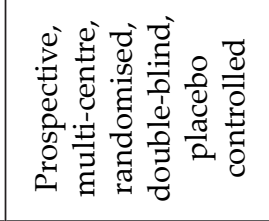 \\
\hline 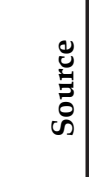 & 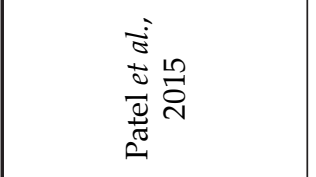 & 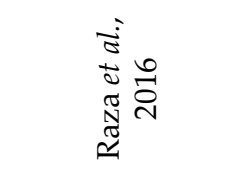 & 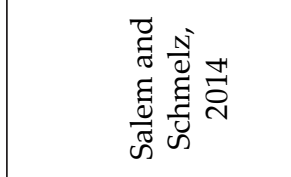 & & 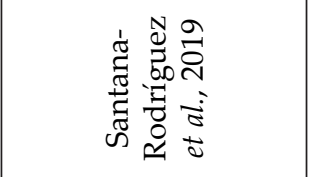 & 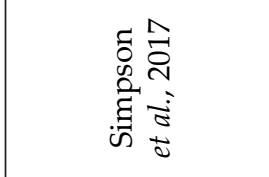 \\
\hline
\end{tabular}




\begin{tabular}{|c|c|c|c|c|c|}
\hline & 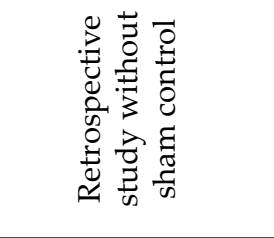 & 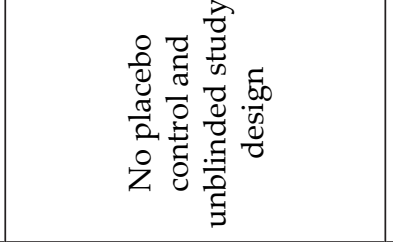 & 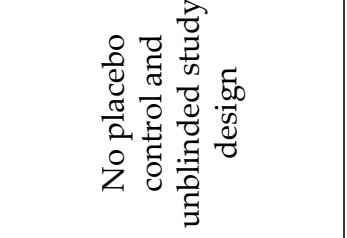 & 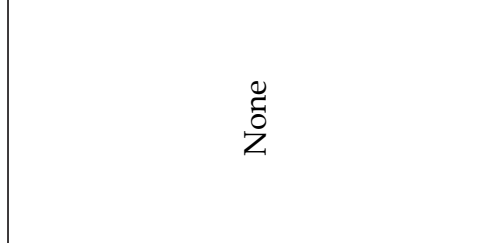 & 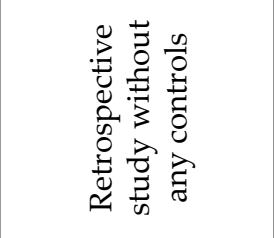 \\
\hline & 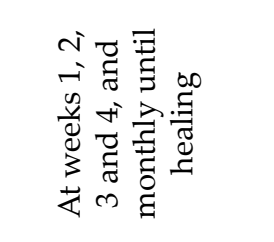 & 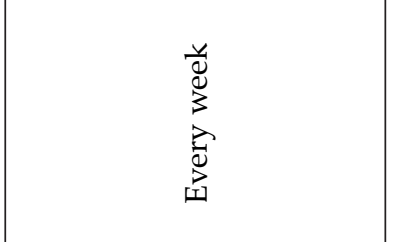 & 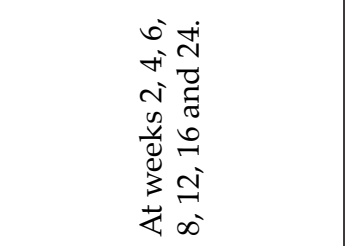 & 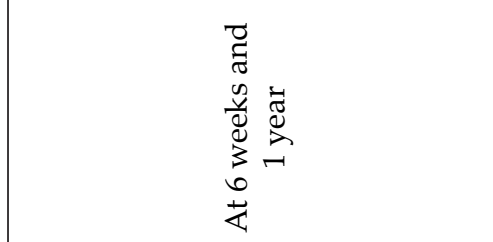 & 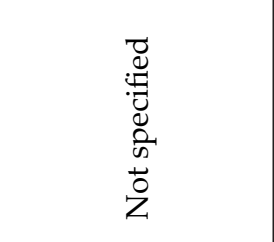 \\
\hline & 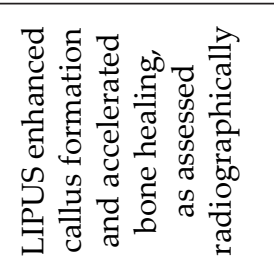 & 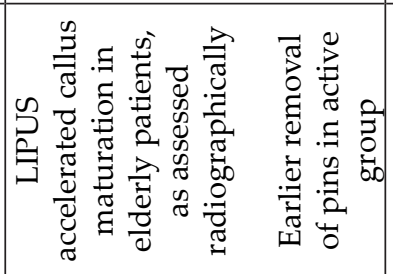 & 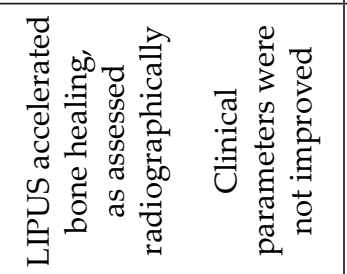 & 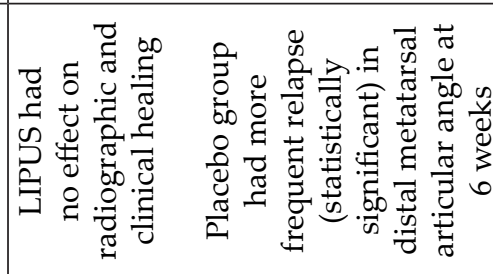 & 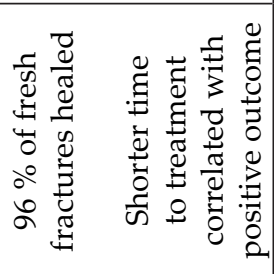 \\
\hline & 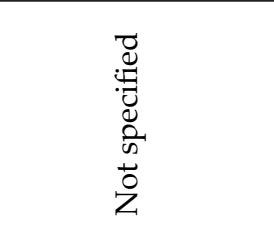 & 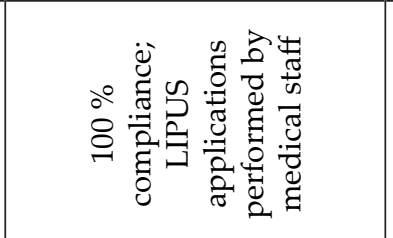 & 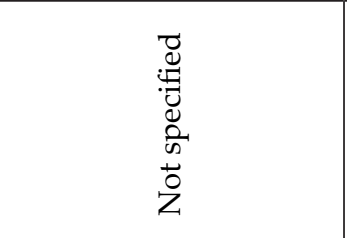 & 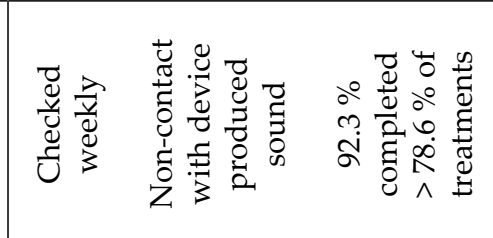 & 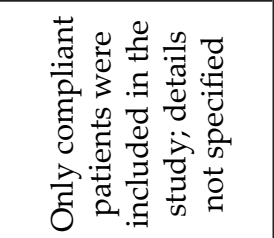 \\
\hline & $\stackrel{2}{2}$ & z & z & $\mathscr{\mathscr { C }}$ & z \\
\hline & $\begin{array}{l}\otimes_{\tilde{J}} \\
8 \\
8 \\
\text { 离 }\end{array}$ & 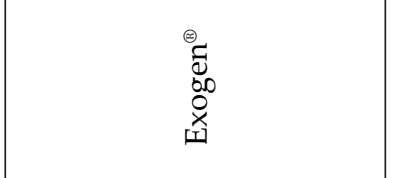 & 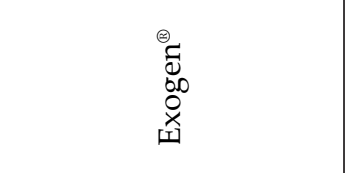 & 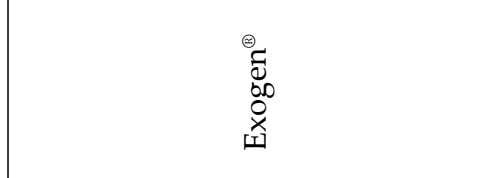 & 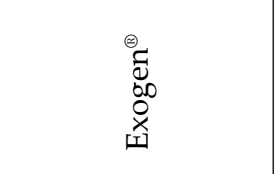 \\
\hline & 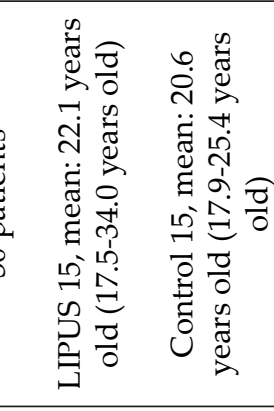 & 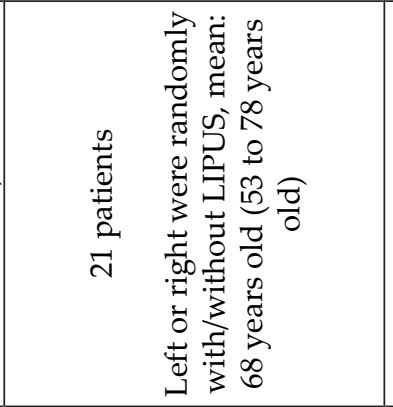 & 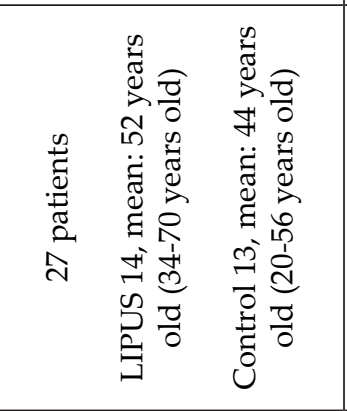 & 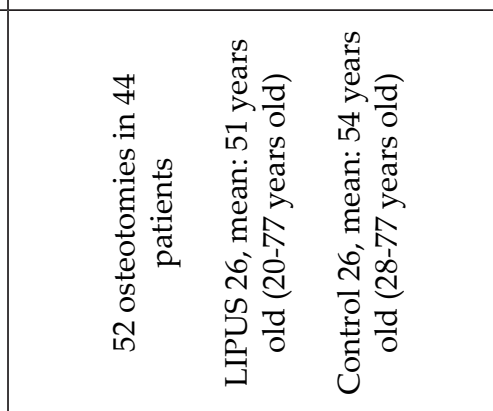 & 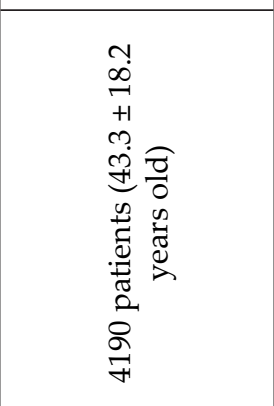 \\
\hline & 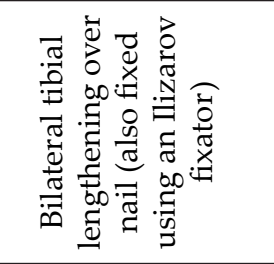 & 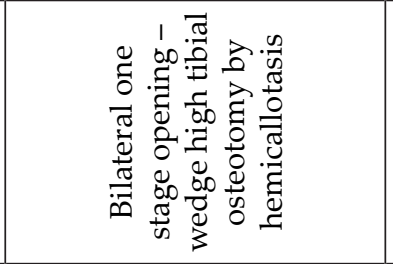 & 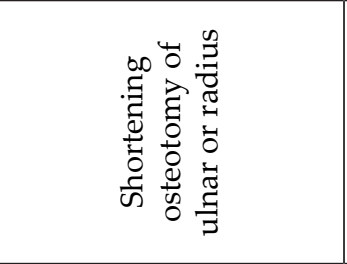 & 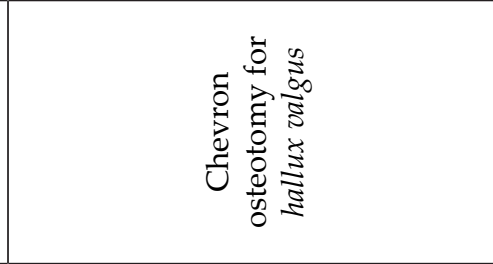 & 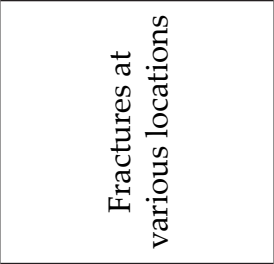 \\
\hline & 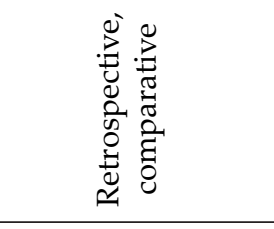 & 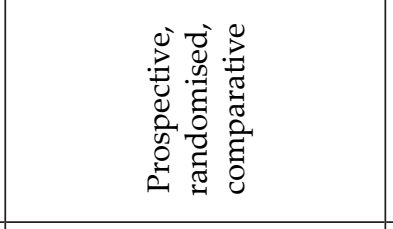 & 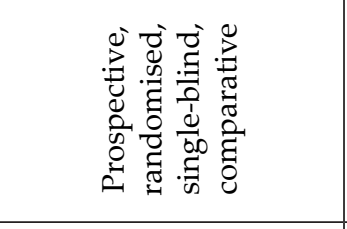 & 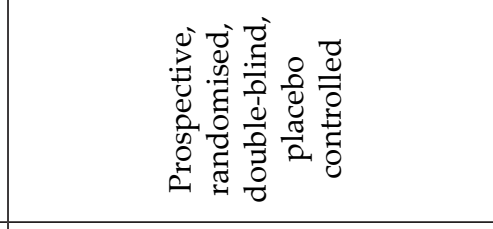 & 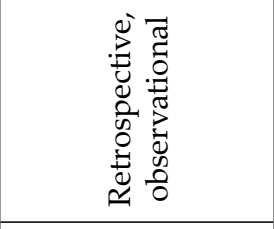 \\
\hline & 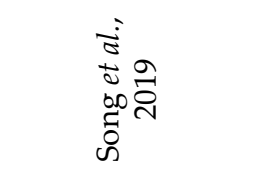 & 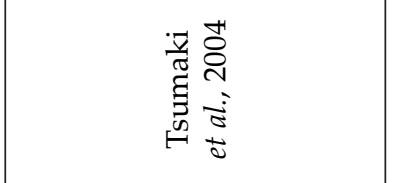 & 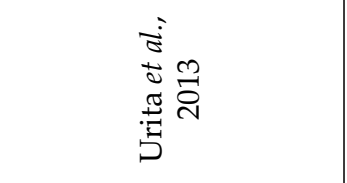 & 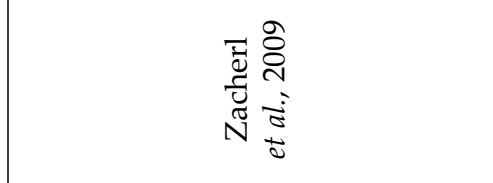 & 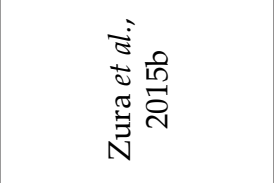 \\
\hline
\end{tabular}


less than $90 \%$ compliance without the appropriate sensitivity analyses. The present review excluded two well-controlled studies, in which fresh tibial fractures (closed or open grade 1) (Heckman et al., 1994) and fractures of the distal radius metaphysis (dorsally angulated, negative volar) (Kristiansen et al., 1997) were immobilised in a cast and treated by LIPUS. Both studies reported that the radiographically assessed healing time was significantly decreased by the LIPUS treatment; however, they were excluded based on a low compliance of $69 \%$ (Heckman et al., 1994) and $72 \%$ (Kristiansen et al., 1997).

It should be further noted that all three unbiased studies (Busse et al., 2014; Emami et al., 1999; TRUST Investigators writing group et al., 2016), as defined by Schandelmaier et al. (2017a), investigated the healing of fresh tibial fractures fixed using only a reamed IM nail. Fractures treated this way are known to have a very low complication rate (Coles and Gross, 2000) and the weight bearing with this type of fixation can start relatively early, due to the immediately acquired stability with the preservation of subtle interfragmentary movement within the fracture gap (Perren, 2002; Schmal et al., 2020). Similarly, a lack of beneficial LIPUS effects was observed in screw-fixed lateral malleolar fractures, providing a possibility of early weight bearing (Handolin et al., 2005a; Handolin et al., 2005b). Therefore, one of the reasons for the lack of pro-regenerative effects might be that the LIPUS application cannot override the benefits of the mechanical loading generated by natural skeletal motion (Malizos et al., 2006). This could be also true for defects with high spontaneous healing rates, where addition of the LIPUS therapy becomes redundant (Gan et al., 2014; Lubbert et al., 2008). The fractures immobilised in the cast, on the other hand, might have a suboptimal mechanical environment and more significantly rely on the wellcontrolled mechanical component of LIPUS and, thus, more profound impacts were observed there (Coughlin et al., 2008; Farkash et al., 2015; Heckman et al., 1994; Kristiansen et al., 1997; Liu et al., 2014; Nolte et al., 2016). These hypotheses should be further tested in preclinical models, using ultrasound setups with well-controlled acoustic parameters (see section "Importance of LIPUS acoustic dose based on preclinical studies"), and in future clinical studies.

\section{LIPUS and bones with compromised healing}

Fractured bones with impaired healing present several challenging tasks for the orthopaedic surgeon. It starts with the difficulty in defining the onset of a delayed-union or non-union and propagates along the decisions on the selected treatment type and time, which must be compliant with the health status including the physiological, psychological and professional demands of the patient (Stewart, 2019). The non-union bone is defined by the FDA as a fracture with no evidence of progressive healing improvement observed in the last 3 months of a total 9-months post-fracture period (Healy et al., 1990).
Whilst the conduction of a RCT involving alternative treatments such as LIPUS is relatively straightforward for the patients with acute fresh fractures, the same procedure involving a largepatient cohort is more challenging to design for a non-union bone. One of the limiting factors is a lack of global standardised definition of delayedand non-union fractures, including the absence of a universal agreement on whether radiographic, clinical or both criteria should be used to characterise those bones (Bhandari et al., 2012; Corrales et al., 2008; Özkan et al., 2019). Surgical intervention is a first-line treatment for most bones with impaired healing (Leng et al., 2019; Özkan et al., 2019; Schmal et al., 2020), whereas ultrasound modalities, such as LIPUS, are considered inefficient (Özkan et al., 2019) and even contraindicated by some orthopaedic surgeons (Busse and Bhandari, 2004; Pounder and Harrison, 2008). A prescription of the LIPUS bonestimulators is usually advised when the surgical intervention carries high risks for the individual (Anderson et al., 2019; Leighton et al., 2017; Zura et al., 2015a). Thus, the to-date evidence for LIPUS effects on delayed- and non-unions (Table 2) mostly relies on either retrospective reports (Adukia et al., 2021; Carlson et al., 2015; Elvey et al., 2020; Farkash et al., 2015; Hemery et al., 2011; Lerner et al., 2004; Mayr et al., 2000; Nolte et al., 2001; Roussignol et al., 2012; Rutten et al., 2007; Teoh et al., 2018; Zura et al., 2015a) or observational studies without placebo controls (Bawale et al., 2020; Biglari et al., 2016; Gebauer and Correll, 2005; Gebauer et al., 2005; Jones et al., 2006; Majeed et al., 2020; Moghaddam et al., 2016).

As far as it can be ascertained, only one multicentre, randomised, placebo-controlled clinical trial evaluating the effects of LIPUS on delayed bone healing (minimal fracture age 4 months) and enrolling a total of 101 subjects with a $91 \%$ final compliance has been performed (Schofer et al., 2010). The study reported an increase in bone-mineral density and a decrease in fracture gap for the LIPUSactive group at the 16-week follow-up, although no statistically significant difference in the number of healed fractures between the groups was found. As it was mentioned by Schandelmaier et al. (2017a), this study could have been biased by the age of the fracture at the start of the trial, as the mean age in the LIPUS-treated group was higher. Although the difference in the fracture-age distribution was found to be not statistically significant (Schofer et al., 2010), a similar study with homogenous fracture age groupings for patients with non-union bones will be of great importance.

Two more studies have evaluated biopsies of fibulae with delayed healing within a randomised double-blind, placebo-controlled trial, revealing that LIPUS increased osteoid thickness and bone mineralisation (Rutten et al., 2008), which, most likely, occurred through the locally enhanced osteogenic differentiation of cells (Rutten et al., 2009). However, both studies were based on very small patient cohorts. 


\begin{tabular}{|c|c|c|c|c|c|c|}
\hline & 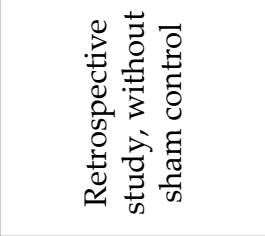 & 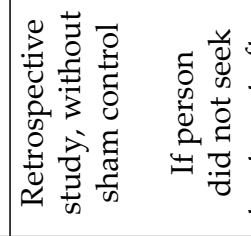 & 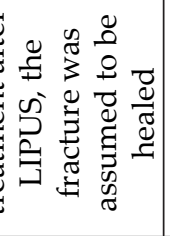 & 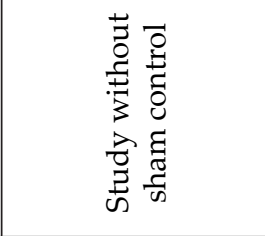 & 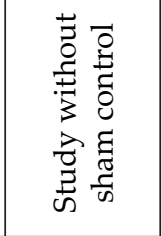 & 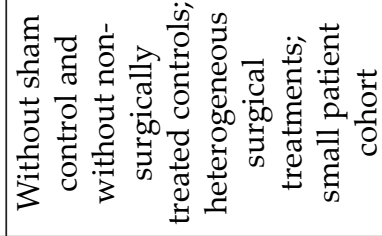 \\
\hline & 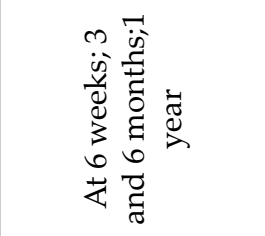 & 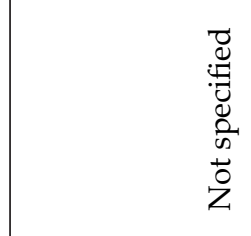 & & 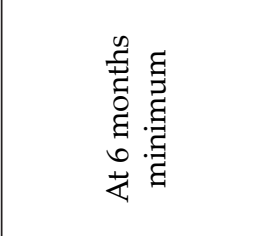 & 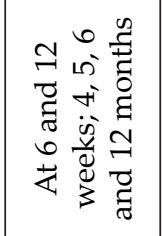 & 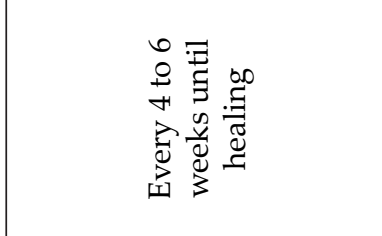 \\
\hline 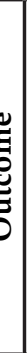 & 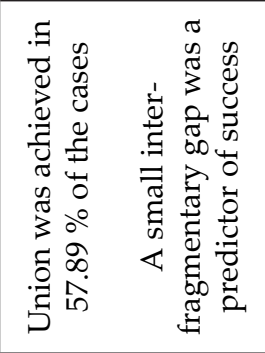 & 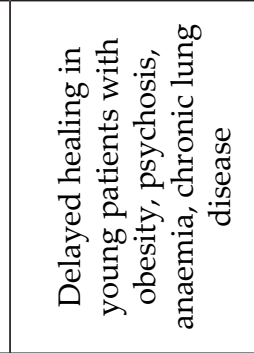 & 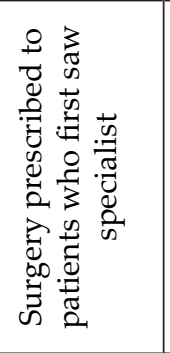 & 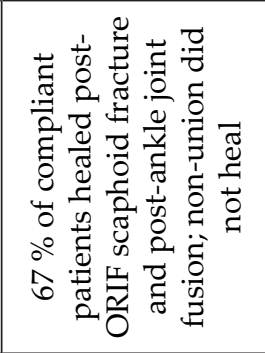 & 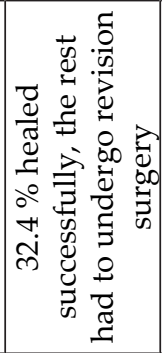 & 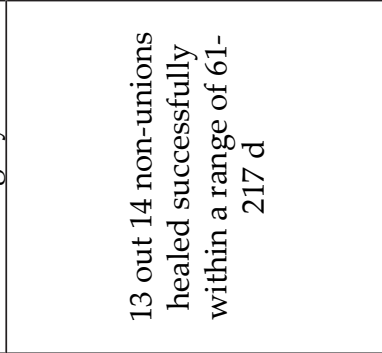 \\
\hline & 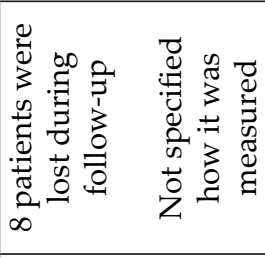 & 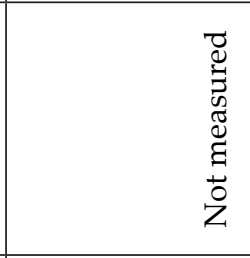 & & 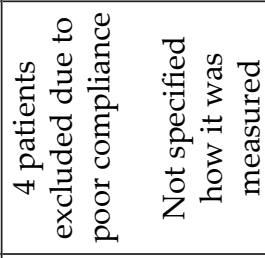 & 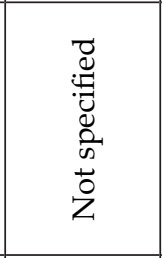 & 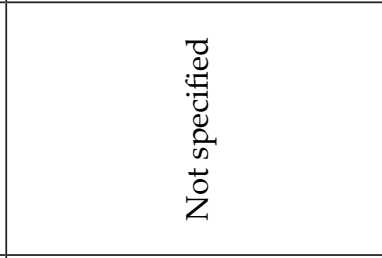 \\
\hline & $\stackrel{\circ}{z}$ & z & & zे & $\stackrel{\circ}{Z}$ & z \\
\hline & 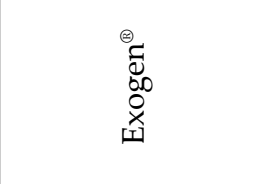 & 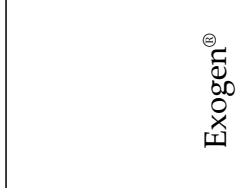 & & 苞 & 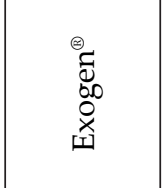 & 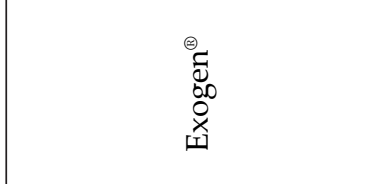 \\
\hline & 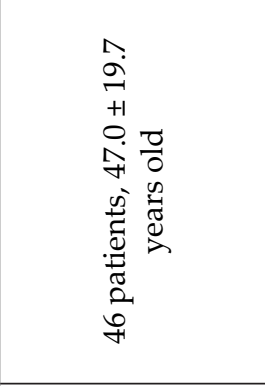 & 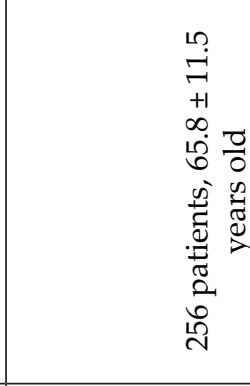 & & 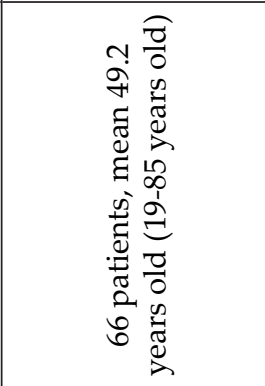 & 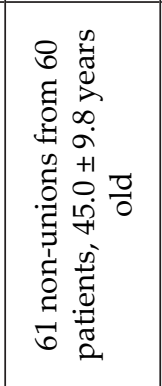 & 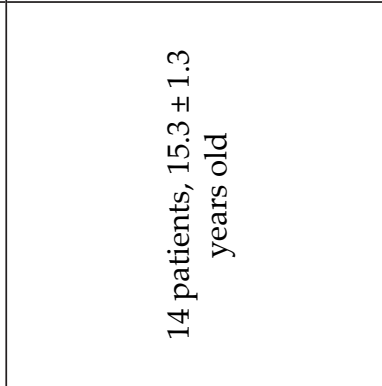 \\
\hline Dै & 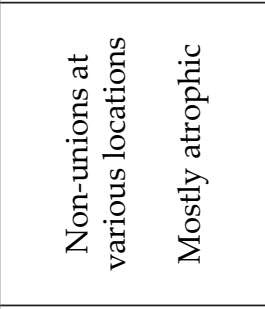 & 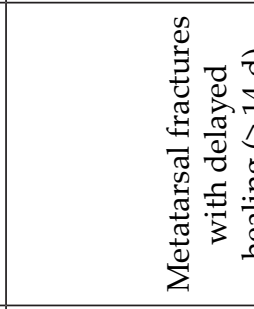 & & 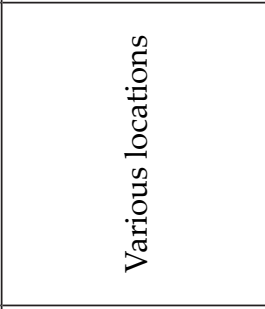 & 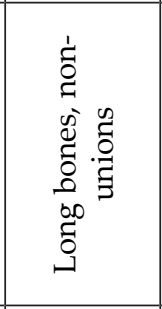 & 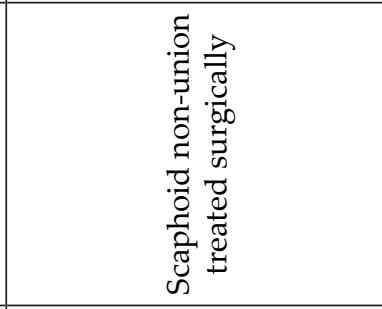 \\
\hline & 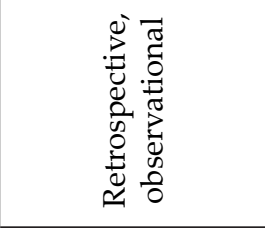 & 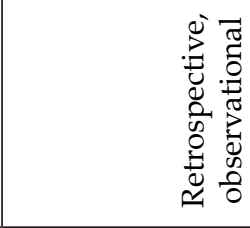 & & 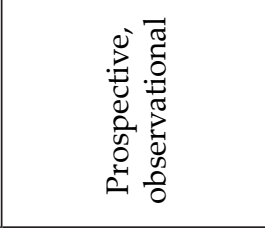 & 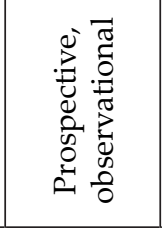 & 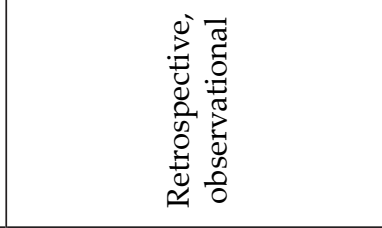 \\
\hline 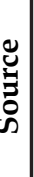 & 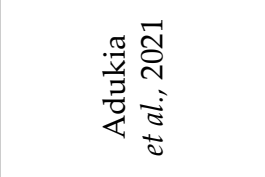 & 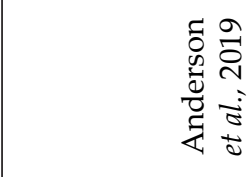 & & 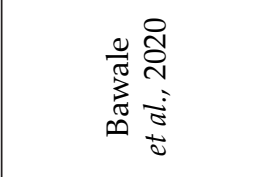 & 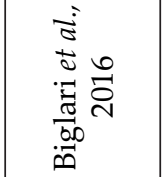 & 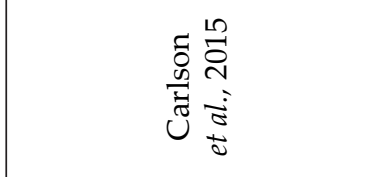 \\
\hline
\end{tabular}




\begin{tabular}{|c|c|c|c|c|c|c|c|c|}
\hline 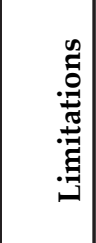 & 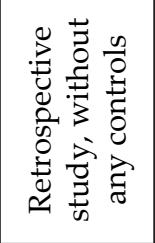 & 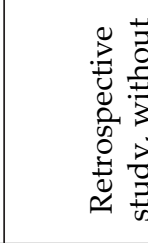 & & 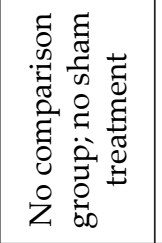 & 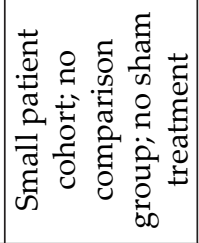 & 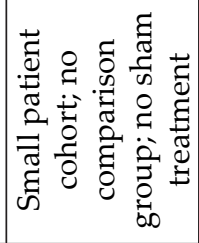 & 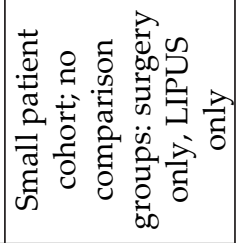 & 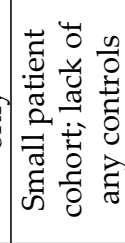 \\
\hline $\begin{array}{l}0 \\
0 \\
\vdots \\
3 \\
0 \\
0 \\
0 \\
1\end{array}$ & 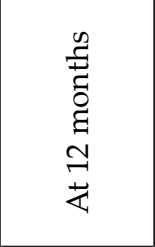 & 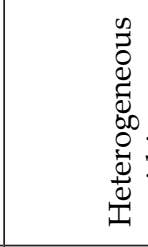 & & 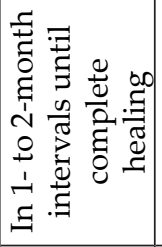 & 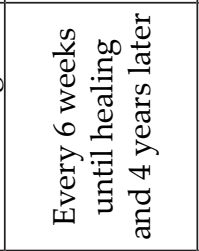 & 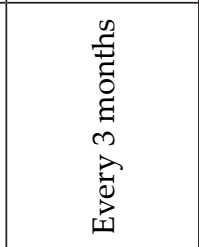 & 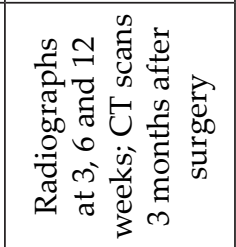 & 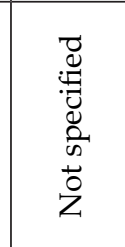 \\
\hline 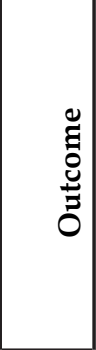 & 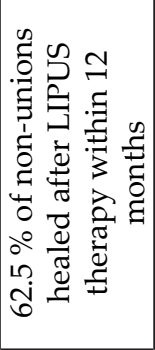 & 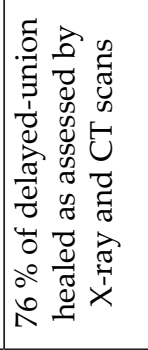 & 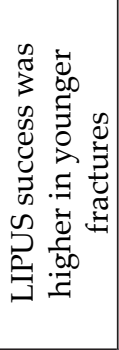 & 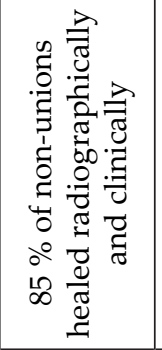 & 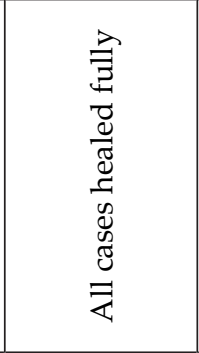 & 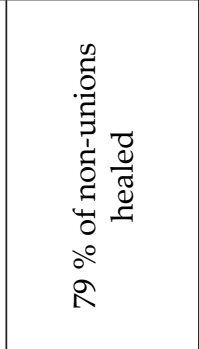 & 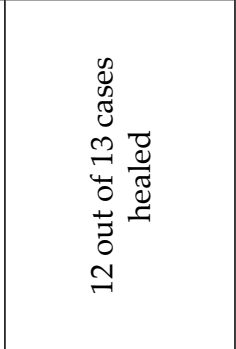 & 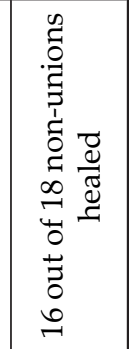 \\
\hline 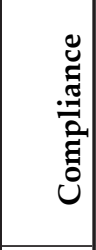 & 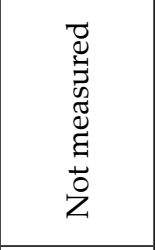 & $\begin{array}{l}0 \\
0 \\
0 \\
0 \\
0 \\
0 \\
0 \\
0 \\
z\end{array}$ & & 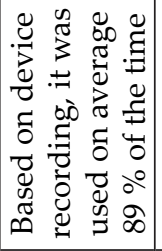 & 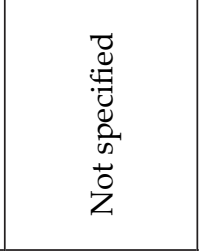 & 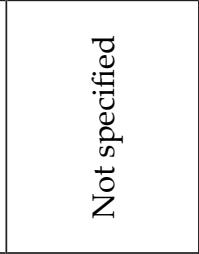 & 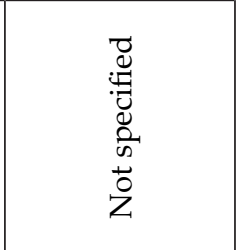 & 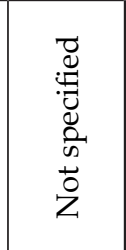 \\
\hline 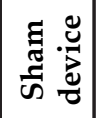 & $\stackrel{\circ}{Z}$ & ż & & 之े & Zे & ż & ż & zे \\
\hline 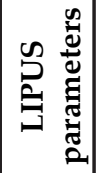 & 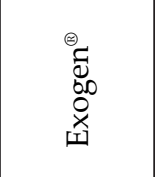 & $\begin{array}{l}\otimes \\
0 \\
0 \\
0 \\
0 \\
x\end{array}$ & & 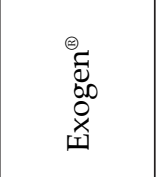 & 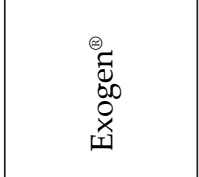 & 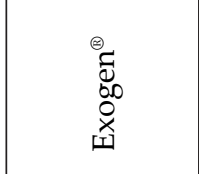 & 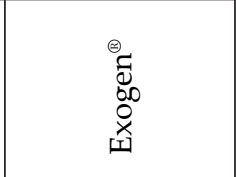 & 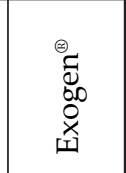 \\
\hline 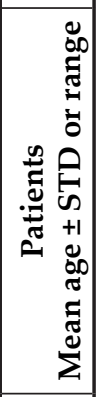 & 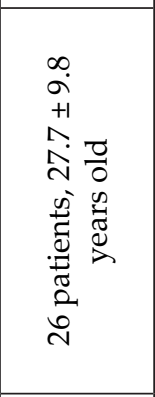 & 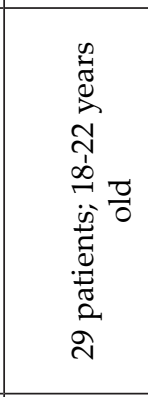 & 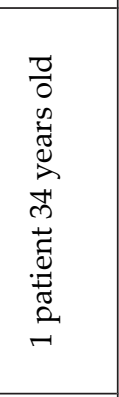 & 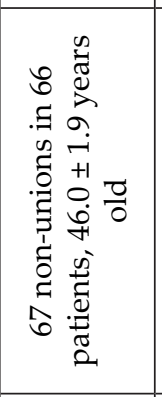 & 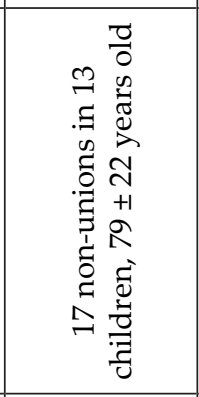 & 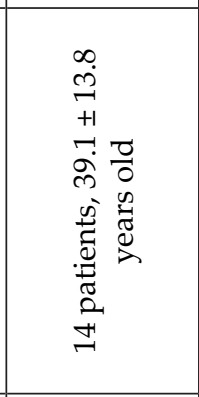 & 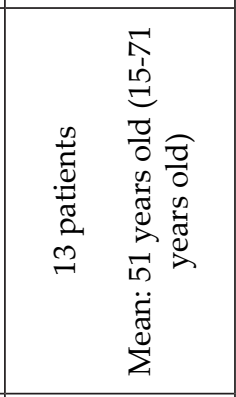 & 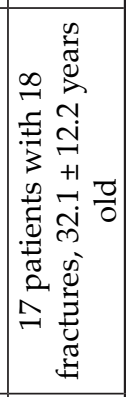 \\
\hline 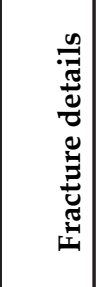 & 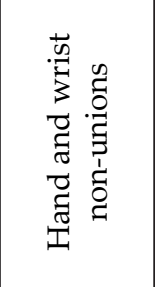 & 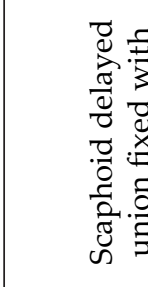 & & 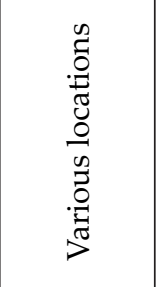 & 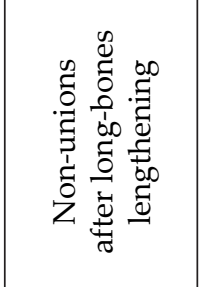 & 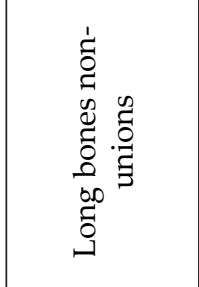 & 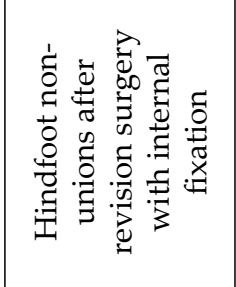 & 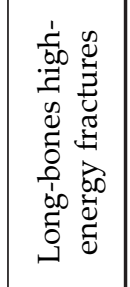 \\
\hline 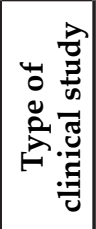 & 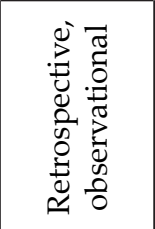 & 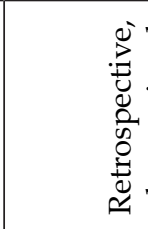 & & 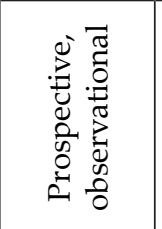 & 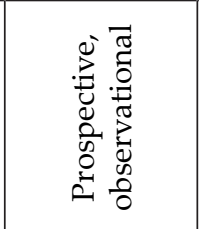 & 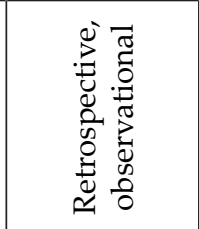 & 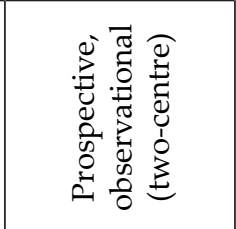 & 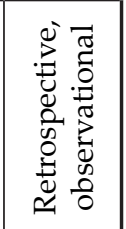 \\
\hline 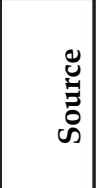 & 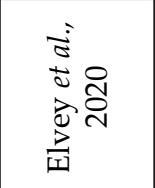 & 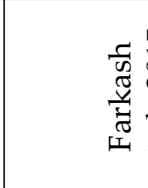 & & 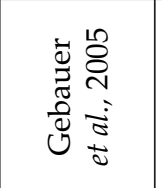 & 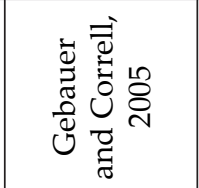 & 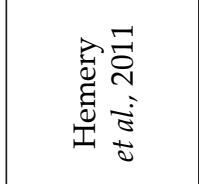 & 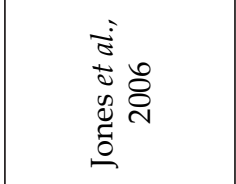 & 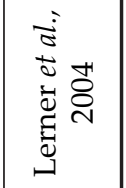 \\
\hline
\end{tabular}




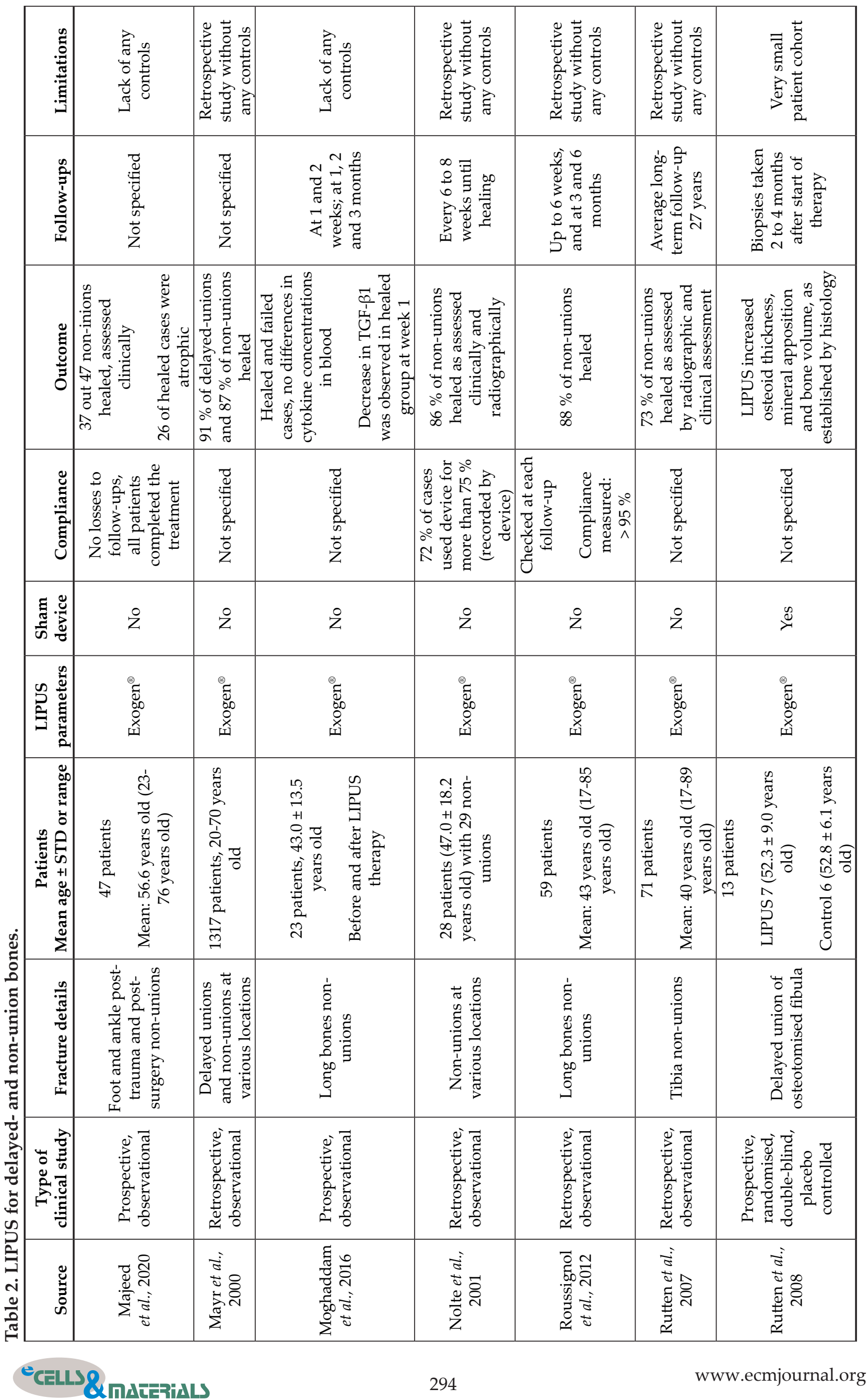




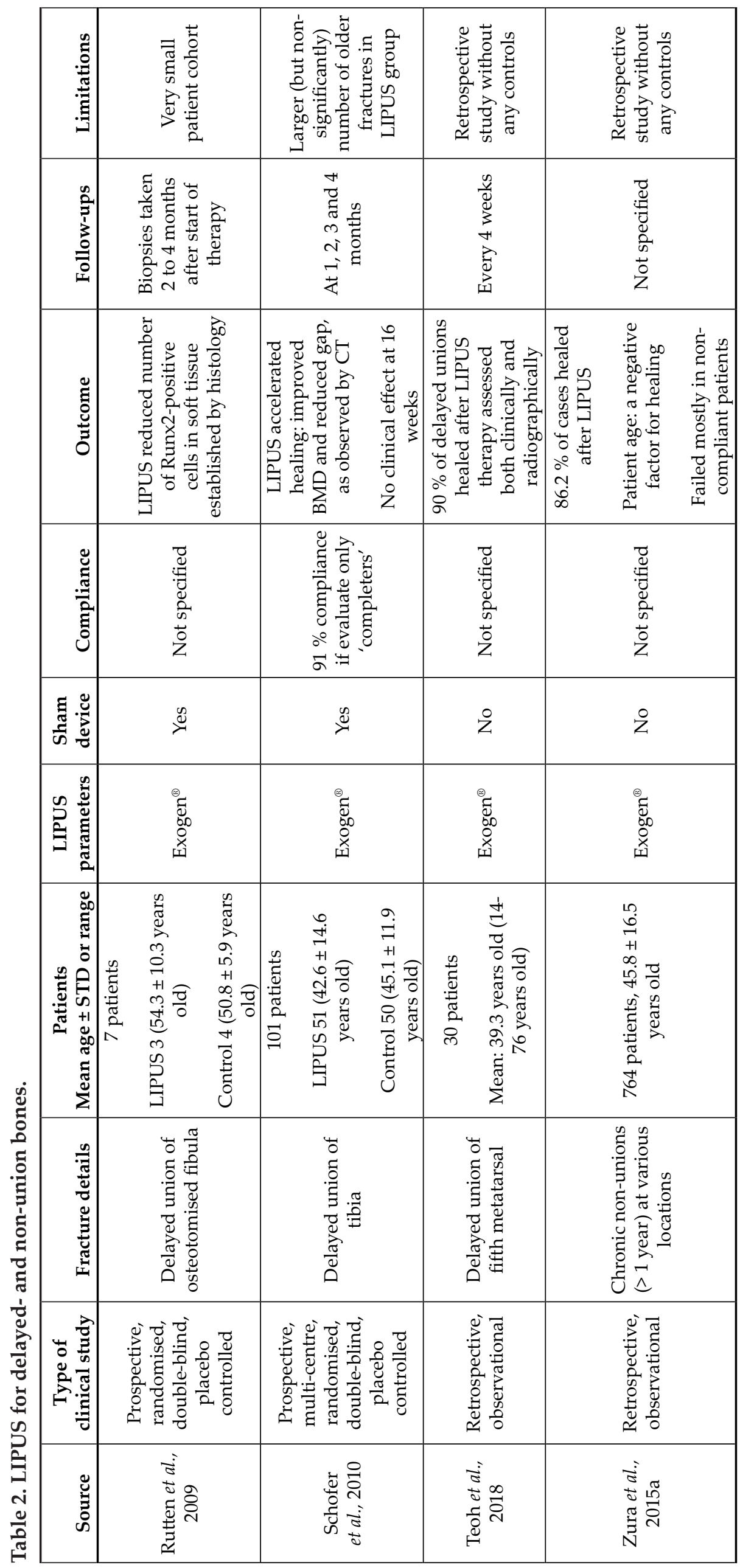




\begin{tabular}{|c|c|c|c|}
\hline 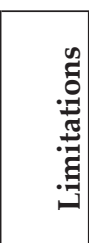 & 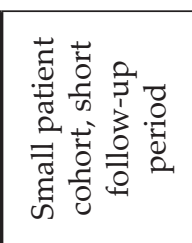 & 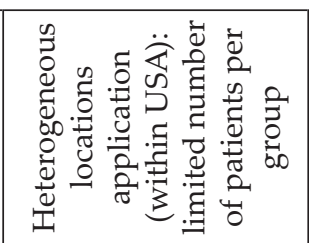 & 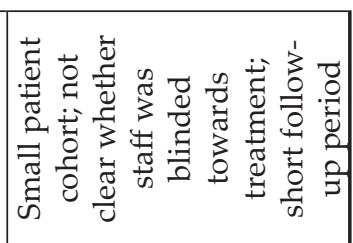 \\
\hline $\begin{array}{l}0 \\
0 \\
\vdots \\
3 \\
0 \\
0 \\
0 \\
0 \\
\end{array}$ & 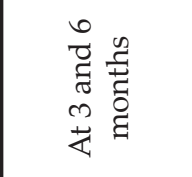 & 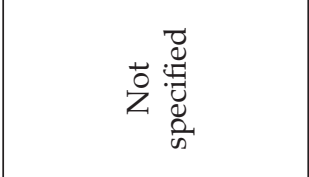 & 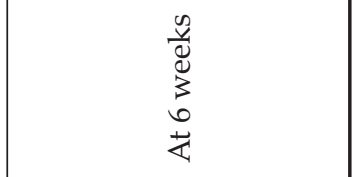 \\
\hline $\begin{array}{l}\text { : } \\
\text { : } \\
\vdots \\
0\end{array}$ & 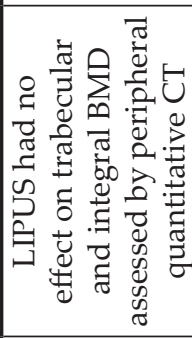 & 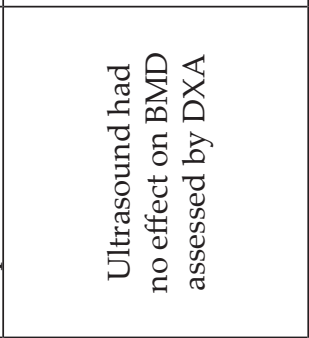 & 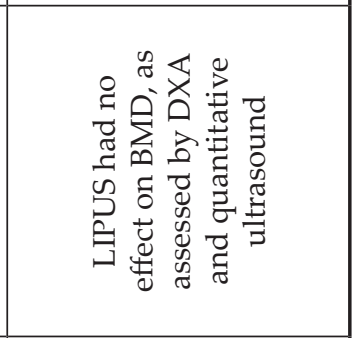 \\
\hline 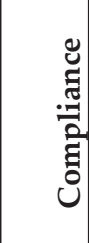 & 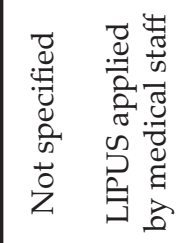 & 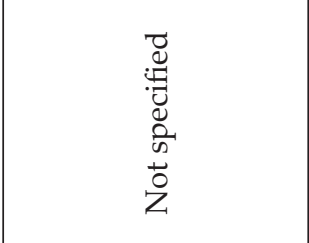 & 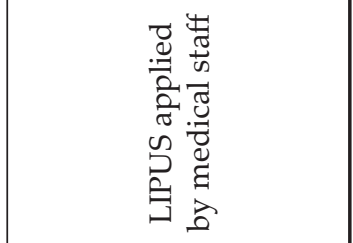 \\
\hline 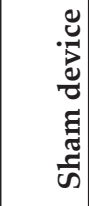 & 之े & Zे & 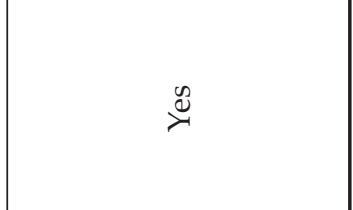 \\
\hline 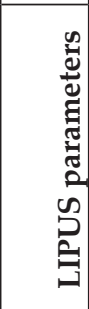 & 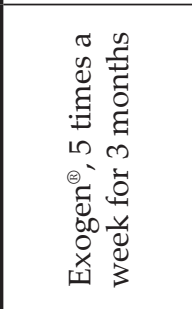 & 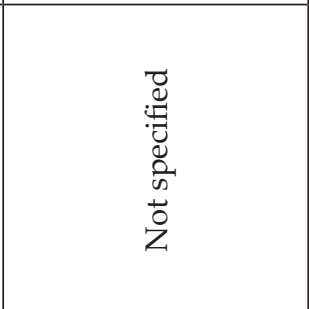 & 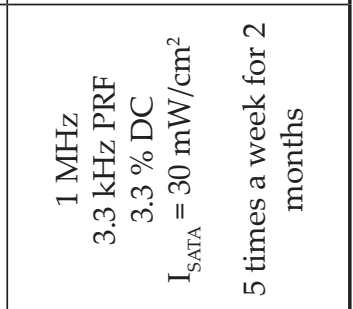 \\
\hline 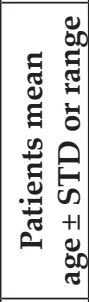 & 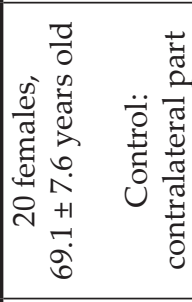 & 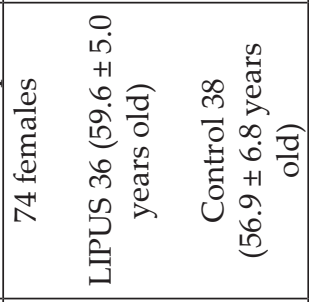 & 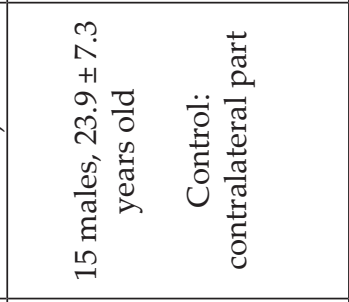 \\
\hline 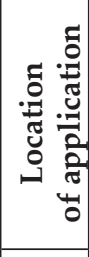 & 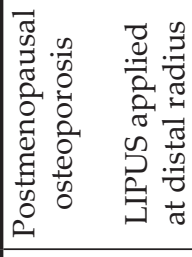 & 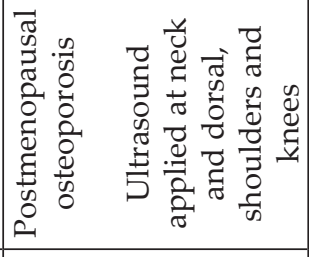 & 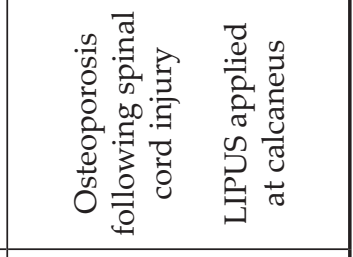 \\
\hline 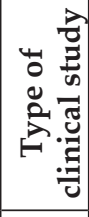 & 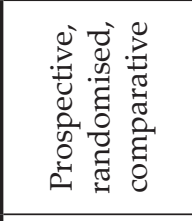 & 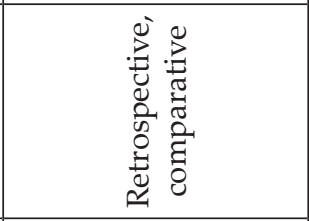 & 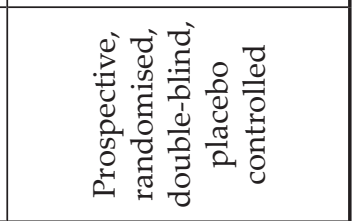 \\
\hline 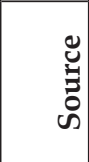 & 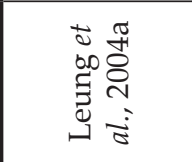 & 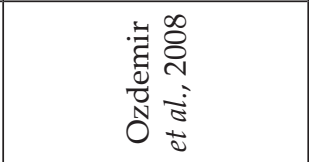 & 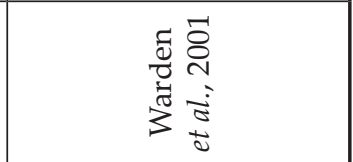 \\
\hline
\end{tabular}


The lack of positive evidence for the LIPUS treatment in fixed fresh fractures, based on the three unbiased studies highlighted above (Schandelmaier et al., 2017a), also advised against the ultrasound technique for patients with non-unions (Poolman et al., 2017; Schandelmaier et al., 2017b). Although one can find this conclusion logical, the biological signatures in acute fractures and chronically impaired non-unions are not alike. These are summarised in the next section.

\section{Biological pathogenesis of non-union bone. Can LIPUS help?}

The local biology at the fracture site, systemic conditions of the host and mechanical stability are the key factors defining the outcome of the fractured bone (Harwood, 2010). When the bone fracture is fixed and interfragmentary movement within the gap is sustained in the proper range, a process of endochondral ossification is usually observed. Through interlinked phases of inflammation, callus formation and remodelling, the fractured bone is reconstituted ad integrum (Loi et al., 2016; Marsell and Einhorn, 2011). If one or more phases of this well-orchestrated process are compromised, a nonunion occurs. Based on radiographic and histological assessments, these non-unions can be further categorised into hypertrophic and atrophic types. For the former, biological aspects are in place, but no adequate stability of the fractured bone exists, resulting in callus formation but hindering callus union, maturation and remodelling. For the latter, the biological components are compromised and, at times, combined with mechanical instability (Volpin, 2014). The hypertrophic non-unions can usually be managed by additional stabilisation of the fractured bone (Nauth et al., 2018), whereas atrophic nonunions are more challenging to treat and complex approaches are often required.

The initial acute inflammation in the bone regeneration process is critical for the resultant organ functionality, as shown in animal studies (Grundnes and Reikeras, 1993a; Grundnes and Reikeras, 1993b; Park et al., 2002). It is usually the strongest within several days to a week and declines with time in a normal healing scenario (Loi et al., 2016). The persistence of an immune reaction can result in chronic inflammation, impaired healing and bone non-union (Bastian et al., 2011; Claes et al., 2012; Hardy and Cooper, 2009; Zura et al., 2016). It has been shown that dendritic cells isolated from bone marrow and stimulated with LIPUS secrete exosomes with enhanced anti-inflammatory potential, which alleviates TNF- $\alpha$-induced inflammation of endothelial cells (Li et al., 2019). The LIPUS treatment also supports the transition of inflammatory to resident macrophages, enhances gene expression of anti-inflammatory factors and improves spinal fusion in a rat animal model (Zhang et al., 2019). The antiinflammatory potential of ultrasound stimulation has been as well described in several other studies (da Silva Junior et al., 2017; Li et al., 2003; Nakao et al., 2014; Yang et al., 2017).

When MSCs are isolated from hypertrophic nonunion fractures, they show strong differentiation potential into all three lineages in vitro, i.e. chondrogenic, adipogenic and osteogenic (Iwakura et al., 2009). The same cell type isolated from atrophic non-unions not only undergo senescence and growth arrest but also have a significantly lower osteogenic differentiation potential (Bajada et al., 2009). The co-stimulation of mesenchymal cells isolated from patients with different non-union types with BMP-7 and LIPUS significantly enhances the osteogenic potential of these cells (Koga et al., 2013). Unfortunately, the effect of LIPUS alone is not described. The expression and activation of BMPs and their antagonists are out of balance in both hypertrophic and atrophic non-union human fractures (Fajardo et al., 2009; Kloen et al., 2002; Kwong et al., 2009a; Kwong et al., 2009b). The application of LIPUS enhances expression of BMP-2, BMP-4 and BMP-7 and their receptors in osteoblasts-like cells (Gleizal et al., 2006; Suzuki et al., 2009a; Suzuki et al., 2009b), which might help to compensate for this imbalance.

Mechanical loading in the properly stabilised fracture induces NO production, which in turn modulates bone adaptation to the applied stimulus (Klein-Nulend et al., 2014). NO signalling is especially deregulated in patients with atrophic non-unions (Wijnands et al., 2012). LIPUS stimulation of osteoblasts augments NO release via nuclear factor- $\kappa \mathrm{B}$ signalling pathway (Hou et al., 2009). NO signalling induces expression of VEGF-A and HIF-1 $\alpha$ in LIPUS-treated osteoblasts (Wang et al., 2004). This promotes tube formation by endothelial cells, which is crucial for angiogenesis and is often debilitated in pathological fractures. NO release also activates other pathways, such as canonical Wnt/ $\beta$ catenin signalling in osteoblasts and osteocytes, which is known to influence bone mass (Krishnan et al., 2006). The secretion of DKK-1, antagonising Wnt-signalling (Pinzone et al., 2009), is enhanced in the culture medium of MSCs isolated from patients with atrophic non-unions (Bajada et al., 2009). LIPUS may be able to counteract this effect, since Wntsignalling is enhanced in stimulated osteoblasts and osteoprogenitors (Olkku et al., 2010).

The expression of MMPs, regulating cell attachment, migration, release of biologically active molecules and invasion of newly formed blood vessels into the callus is also alleviated in non-union fractures (Ortega et al., 2003). The decrease in expression of MMP-2, -9 and -13 in non-union fractures results in impaired bone remodelling (Ding et al., 2018). LIPUS mechanical stimulus enhances MMP-13 expression in long-term cultured osteoblasts (Unsworth et al., 2007), which could potentially improve ECM turnover, critical for successful tissue regeneration.

The key biological signatures of a non-union fracture and the hypothetical LIPUS effects influencing 
them are summarised in Fig. 2. Despite the positive evidence of LIPUS stimulation, most of the studies described in this section revolve around cell-lines or cells isolated from bones with uncomplicated healing scenario. Whether LIPUS can have similar effects on cells from atrophic and hypertrophic nonunions is a question worth further investigation that needs to be addressed in vitro and in appropriate preclinical models. To the authors' knowledge, only two preclinical in vivo studies, investigating the effects of LIPUS on a hypertrophic non-union, have been published so far, demonstrating contradictory findings (Takikawa et al., 2001; Volpon et al., 2010).

\section{LIPUS for aged and osteoporotic patients}

With progressing age, the human skeleton undergoes cortical-bone thinning, increased trabecular spacing and expansion of the medullary cavity (Javaheri and Pitsillides, 2019). These morphological changes and overall bone homeostasis are results of systemic changes to biochemical signalling pathways of the human body, eventually leading to impaired mechanoadaptation and compromised fracture regeneration (Haffner-Luntzer et al., 2016). Aged individuals experience a reduction in osteoprogenitor cells (Kasper et al., 2009), with a reduced osteogenic potential (D'Ippolito et al., 1999; Ross et al., 2000) and an altered response to mechanical stimulation (Kasper et al., 2009). Additionally, changes in shape of osteocytes and the number of canaliculi per lacuna are found in aged organisms, which dampens their mechanosensitivity and could result in an inefficient interaction between osteoblasts and osteoclasts (Hemmatian et al., 2017). The mechanical stimulation of chronic non-unions with LIPUS in aged patients has shown certain promise, although the fracture-healing rate declines moderately with increasing age (Zura et al., 2015a). MSCs isolated from aged rats experience enhanced expression of osteogenic markers, i.e. Runx-2 transcription factor and osteocalcin, when stimulated with high intensity LIPUS, in comparison to cells isolated from young rats (Puts et al., 2016a). This might imply that due to changes in mechano-responsiveness of the osteoprogenitors with increasing age, an adjustment of the LIPUS-stimulation protocol is required. The accelerated fracture healing following LIPUS exposure was also confirmed in in vivo studies performed with aged rodents (Aonuma et al., 2014; Katano et al., 2011); however, the relevance of these results for the clinical setting remains questionable due to the animal size in relation to the area of the transducer (see section "Importance of LIPUS acoustic dose based on preclinical studies").

Osteoporosis is a chronic metabolic bone disorder that more commonly affects postmenopausal women and, given the increasing life expectancy, is becoming a global health challenge (Cauley, 2017). Medicationfree therapies for the management of this disease represent a very appealing research topic (Kasturi and Adler, 2011b; Yadollahpour and Rashidi, 2017). Application of LIPUS as a treatment option for postmenopausal bone-loss has been investigated previously and no positive effects on the BMD were observed (Leung et al., 2004a; Ozdemir et al., 2008) (Table 3). Another study in young male patients with spinal cord injury, experiencing up to $70 \%$ bone loss, comparable to 5 years of bone depletion due to osteoporosis, found that LIPUS stimulation of the calcaneus bone did not influence its bone mineral content (Warden et al., 2001). In this study, shorter pulses of ultrasound stimulation were used and the frequency of the sine wave was $1 \mathrm{MHz}$ in comparison to the $1.5 \mathrm{MHz}$ conventional stimulation frequency (Table 3). In contrast, several in vivo studies using an ovariectomised rat osteoporosis model have shown the beneficial effects of LIPUS exposure on improvement of the disease markers (Carvalho and Cliquet Junior, 2004; Ferreri et al., 2011; Wu et al., 2009). Given the size of the LIPUS-probe, the anabolic

\begin{tabular}{|c|c|}
\hline Pathogenesis of non-union & Possible effects of LIPUS \\
Inflammation $\uparrow$ & Inflammation $\downarrow$ \\
Osteogenesis of MSCs $\downarrow$ \\
BMPs vs. antagonists imbalance \\
NO signalling $\downarrow$ \\
Angiogenesis $\downarrow$ \\
Wnt signalling $\downarrow$ \\
ECM remodelling $\downarrow$
\end{tabular}

Fig. 2. Can LIPUS help regenerate a non-union? Biological signatures of non-union bone (left) and hypothetical effects of LIPUS-stimulation on non-union regeneration (right). 
effects of ultrasound in rodents might partially mimic a low-magnitude high-frequency whole-body vibration therapy, which shows promising results in improving BMD in postmenopausal women (Kasturi and Adler, 2011a; Lai et al., 2013; Rubin et al., 2004; Verschueren et al., 2004).

Although stimulation with LIPUS represents an appealing medication-free treatment for osteoporosis, this chronic metabolic disorder has a systemic nature and will not likely succumb to local stimulation with ultrasound. As discussed by Warden et al. (2001), the losses associated with the ultrasound propagation constrain the acoustic stimulation to a very restricted volume. Although the current clinical LIPUS set-up and protocol most likely has limited potential for the treatment of osteoporosis, the investigation of the LIPUS application for regeneration of fractures in aged, osteoporotic patients and patients with other co-morbidities is of great interest.

\section{LIPUS and patient compliance}

Patient compliance with the treatment regimen can profoundly affect the outcome of a clinical trial. As was demonstrated by Czobor and Skolnick (2011), non-compliant patients can disguise the efficacy of a tested therapy. In this study, the compliant patients were screened out based on the detection of the drug metabolite in their blood over the course of treatment. A comparison of the compliant patients, which comprised $70 \%$ of the patients, to the placebo group confirmed the drug's efficacy, whereas the non-compliant group did not differ from the control. Moreover, the same compliance assessed by counting consumed pills was more than $92 \%$. Adherence to the study protocol carries even a bigger challenge for treatments outside the medical facility, resulting in a biased data interpretation (Pounder et al., 2016; Pullar et al., 1989). LIPUS application is usually prescribed to the patients as a long-term treatment and requires a 20 min time window every day. Therefore, motivation and dedication of the patients plays an indispensable role in the study outcome. Certain factors, such as age and fracture site, could significantly affect the adherence to the prescribed LIPUS protocol (Matsubara et al., 2015). The detailed description of patient compliance in the reviewed studies is summarised in Table 1-3.

There is a considerable variability in documentation regarding patients' compliance in LIPUS clinical trials. Some studies reported the number of patients available at the end of the treatment out of the whole sample, whereas others additionally supplied the number of days and min/d of LIPUS application accomplished by the patients. It is not always clear, though, whether the active minutes were counted only when the device was in direct skin contact, as it was described in some studies (Emami et al., 1999; Zacherl et al., 2009). Overall, there is a trend towards positive regenerative outcomes of the LIPUS application in clinical trials with increasing patient device-application compliance (Gopalan et al., 2020;
Maurya et al., 2019; Namera et al., 2020; Nolte et al., 2001; Roussignol et al., 2012; Santana-Rodríguez et al., 2019; Schofer et al., 2010; Tsumaki et al., 2004). Studies, where around $30 \%$ of the patients performed less than $50 \%$ of LIPUS applications found LIPUS ineffective (Emami et al., 1999; TRUST Investigators writing group et al., 2016; Simpson et al., 2017). As an example, exclusion of non-compliant patients (as reported by the recordings on the device) in a study of LIPUS-treated non-unions revealed prohealing effects of sonication comparable to surgical intervention (Bawale et al., 2020). Studies, where the compliance is not descriptively documented are ambiguous regarding the efficacy of LIPUS therapy (Table 1-3).

A stringent weekly control of adherence to the prescribed protocol, requiring a minimum 15 min-long skin contact with the device through a coupling gel, resulted in an excellent compliance in 44 patients after chevron osteotomy for hallux valgus (Zacherl et al., 2009). A profound impact on bone formation was observed in the LIPUS-active group, whereas a relapse in a first distal metatarsal articular angle 6 weeks after treatment was reported in the placebo group. The active support of patients and communication with the medical personnel seem to improve the compliance significantly, favouring LIPUS therapy (Arimoto et al., 2019; Gopalan et al., 2020; Maurya et al., 2019; Namera et al., 2020; Patel et al., 2015; Santana-Rodríguez et al., 2019; Tsumaki et al., 2004; Zacherl et al., 2009). This should be considered when planning a clinical trial. New generation Exogen ${ }^{\circledR}$ devices might also help raising patients' awareness on the treatment progress and support their motivation through direct feedback of an integrated calendar (Pounder et al., 2016). In summary, an inclusion in the scientific studies of the detailed information on the number of completed days and minutes of LIPUS treatment, along with a population size that was intended to be treated and actually adhered to the protocol, can aid an adequate judgment of LIPUS therapy.

\section{Importance of LIPUS acoustic dose based on preclinical studies}

The clinically most used LIPUS parameters $[1.5 \mathrm{MHz}$ frequency, $1 \mathrm{kHz}$ PRF, $20 \%$ DC and $30 \mathrm{~mW} / \mathrm{cm}^{2} \mathrm{I}_{\text {SATA }}$ $\left(\right.$ Exogen $\left.^{\circledR}\right)$ ] originate from a preclinical rabbit model (Duarte, 1983). Since then, little effort has been made to optimise this acoustic dose. With the exception of 9 studies (see Materials and Methods, and Table 1 and 3), the rest of the studies applied Exogen ${ }^{\circledR}$-like parameters.

The current evidence for LIPUS-induced proregenerative potential in bone shows pronounced positive effects in cell culture (Padilla et al., 2016; Pounder and Harrison, 2008) and in animal studies (Azuma et al., 2001; Shakouri et al., 2010; Wang et al., 1994). However, it seems that these studies hyperbolise the degree of the LIPUS pro-regenerative potential, which does not coincide with the clinical 
findings (Emami et al., 1999; Poolman et al., 2017; Schandelmaier et al., 2017a).

The two most described in vitro LIPUS set-ups, transmitting ultrasound through gel from the bottom of the tissue culture plate or through the medium from the top of the cells, exposes them to the near field of the transducer, which is prone to large spatial and temporal intensity variations (described in detail by Padilla et al., 2014). Although Harrison et al. (2016) argued that the near-field ultrasoundstimulation represents the closest configuration to the clinical setting, the cells and transducer, in those in vitro experiments, are usually separated by several $\mathrm{mm}$. This exposes the cells to the most heterogeneous proximal near-field of the transducer (Padilla et al., 2014), whereas the clinical device stimulates the fracture site in the mid or far nearfield of the transducer (Harrison et al., 2016), where the amplitude differences are dampened. The in vitro configurations with focused transducers or far-field stimulation (Horne et al., 2020; Puts et al., 2016b; Subramanian et al., 2013) can help to account for these variables. Additionally, the most described in vitro set-ups (Padilla et al., 2014) can subject the cells to physical artefacts, such as multiple reflections and standing waves (Hensel et al., 2011; Mortazavi et al., 2016), and, especially for the gel-coupled configurations, to temperature elevation (Leskinen and Hynynen, 2012). These are, most likely, hardly present in the clinical configurations and should be further evaluated starting with in silico analyses.

The Exogen ${ }^{\circledR}$ LIPUS-probe, widely used in preclinical studies, has a diameter of $22 \mathrm{~mm}$, which exposes the stimulated site to an effective area of $3.88 \mathrm{~cm}^{2}$. If the probe is applied to the femur of a laboratory Wistar rat for example, whose average femur length is $39 \mathrm{~mm}$ (Prodinger et al., 2018), more than $50 \%$ of the bone is coupled with the transducer.
In contrast, a human femur is on average $440 \mathrm{~mm}$ long (Polguj et al., 2013), which results in a $5 \%$ overlap between the bone and the LIPUS-probe. The femur length of a white New Zealand rabbit, another animal often used in in vivo studies showing positive influence of LIPUS (Pilla et al., 1990; Shakouri et al., 2010), is around $94 \mathrm{~mm}$ (Polguj et al., 2013) and more than $20 \%$ of the bone overlaps with the gel-coupled stimulating probe. These in vivo studies apply LIPUS in a manner exactly opposite to the proportional adjustment of the mechanical dose. Subsequently, the smaller the bone treated with LIPUS is, the larger and more diverse resident cell populations embraced by the mechanical stimulation are-including the ones in the bone epiphyses where a large cancellous bone area, rich in stem cells and vasculature, is observed (Gurevitch et al., 2007). This, in turn, can intensively promote migration of the osteoprogenitors to the fracture site, attract immune cells and induce angiogenesis, promoting osteogenesis (Filipowska et al., 2017; Lancerotto and Orgill, 2014). Additionally, the thin soft-tissue layers and small bone-circumferences of a rat result in a stimulation of the fracture in the most heterogeneous near-field of the transducer. Fig. 3a, depicting the numerical simulation of the ultrasound field generated by the Exogen ${ }^{\circledR}$ probe, shows how large the stimulation area of a fractured rat femur with LIPUS is and how high are the intensity fluctuations in the near field of the transducer. When the same femur was positioned in the simulated field of a focused transducer (Fig. 3b), the geometrically confined and acoustic dose-controlled exposure of the bone gap region was achieved. The geometry of the simulated field in Fig. $3 \mathbf{b}$ is similar to the one created by a custom-made scanning acoustic microscope (SAM200 Ex, Q-Bam, Halle, Germany) (Rohrbach et al., 2013).

In contrast to the unproportional scaling down of a

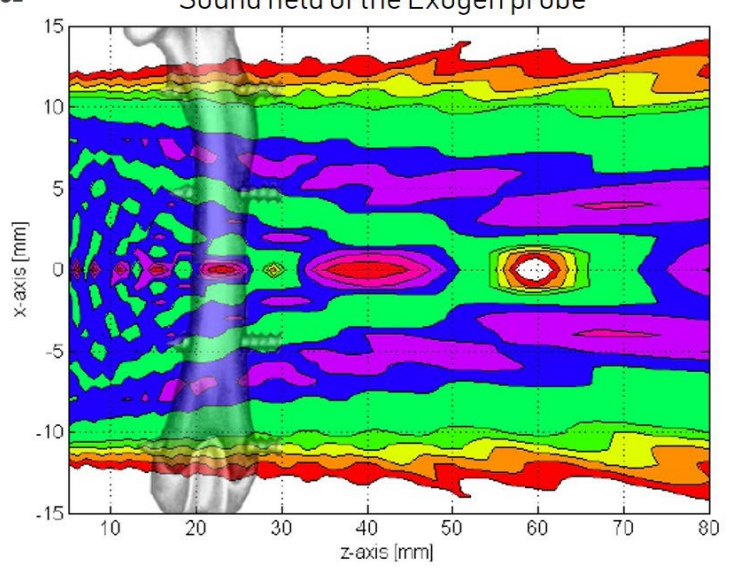

b

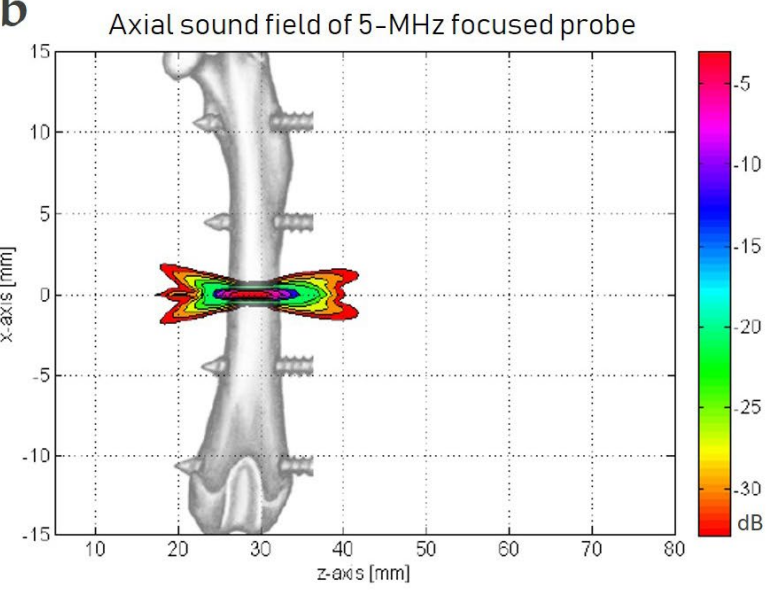

Fig. 3. Schematic drawing of a fractured rat-femur positioned in a simulated sound field produced by (a) a clinically used Exogen ${ }^{\circledR}$ probe and (b) a $5 \mathrm{MHz}$ focused probe producing a $-6 \mathrm{~dB}$ spot of $7.4 \times 0.6 \mathrm{~mm}$. (a) The fracture or osteotomy gap region was exposed to a highly inhomogeneous near field of the transducer and almost the entire femur received the acoustic stimulation. (b) The acoustic energy was deposited in the gap region only. The simulations were performed using Field II program and showed transmit temporal peak intensity. The pin locations of a typically used external fixation device (Rohrbach et al., 2013) are also shown. 
the acoustic dose from the clinical setting to in vivo and in vitro, is the application of BMP-2, a potent growth factor for regeneration of complex boneinjuries and non-unions (Schlundt et al., 2018). The induction of bone healing by BMP-2 in the clinic is performed at a concentration of either $1 \mathrm{mg} / \mathrm{mL}$ or $1.5 \mathrm{mg} / \mathrm{mL}$ (Carter et al., 2008; Govender et al., 2002; Hwang et al., 2016), whereas the same growth factor is used in vivo in rats and rabbits at concentrations ranging from $200 \mathrm{ng} / \mathrm{mL}$ to $37.5 \mu \mathrm{g} / \mathrm{mL}$ (Chen et al., 2018; Hyun et al., 2005; Koolen et al., 2019; Seong et al., 2020; Zara et al., 2011; Zhao et al., 2016). In vitro, cells are usually stimulated using $50-5,000 \mathrm{ng} / \mathrm{mL}$ of BMP2 (Chen et al., 2018; Chen et al., 2019; Kim et al., 2013; Ning et al., 2019). Although supraphysiological doses of the growth factor are used in clinics, the studies elucidating the mechanisms attempt to adjust the concentration of BMP-2 to the size of the stimulated biological system. Exactly the opposite is done with the LIPUS stimulation experiments. This might explain the significant difference in results obtained from small-animal long bones fixed with an IM nail and stimulated with ultrasound, where pronounced bone-healing effects were observed (Azuma et al., 2001; Wang et al., 1994), and the unsuccessful clinical cases (Busse et al., 2014; Emami et al., 1999; TRUST Investigators writing group et al., 2016). To compare adequately the influence of LIPUS on in vivo bone regeneration in small animals and translate these findings to the clinical setting, set-ups with wellcontrolled physical effects need to be applied (Horne et al., 2020; Puts et al., 2016b; Subramanian et al., 2013). Then, further optimisation of the reproducible clinical acoustic dose might be required (Warden, 2003; Warden et al., 2000). Until it is possible to decipher the essential mechanisms of bone regeneration by the defined acoustic stimulation, using the spatially adjusted set-ups translated from human to preclinical models, in vitro and back, the potential benefits of LIPUS will remain underestimated in the clinic.

\section{Discussion}

Upon the onset of a long-bone fracture, the orthopaedic surgeon has to make rapid and efficient decisions as to what are the best treatment options for the patient. The new generation of surgeons more frequently refer to invasive treatments with fixation even for uncomplicated fractures (Courtney et al., 2011; Fernandez, 2005; Schmidt et al., 2003). This, on one hand, provides the desired mechanical stability and ensures adequate conditions for bone regeneration. On the other hand, surgical interventions are prone to infections, which ultimately impair bone healing and result in bone non-unions (Coles and Gross, 2000). Not only are these economically burdensome (Hak et al., 2014; Heckman and Sarasohn-Kahn, 1997; Majeed et al., 2020; Teoh et al., 2018) but also the established non-union bone is often hard to diagnose because the blood inflammatory markers remain within the reference levels in up to $20 \%$ of those cases (Bishop et al., 2012; Nauth et al., 2018). Given these and other risks that the surgical procedures have, they cannot be used as a universal treatment solution: elderly individuals with chronic metabolic disorders and other underlying health conditions as well as people with certain lifestyles where the long recovery time is not desired, are the candidates for alternative methods (Anderson et al., 2019; Bawale et al., 2020; Berber et al., 2020; Cook et al., 1997; Leighton et al., 2017; Nolte et al., 2001; Zura et al., 2015a).

Within the process of bone healing, a miscommunication between the components of the "diamond concept" (Fig. 4), essential for successful bone regeneration, could result in a complicated healing scenario (Andrzejowski and Giannoudis, 2019; Giannoudis et al., 2007). When all 4 facets of the concept, i.e. cells, matrix, growth factors and mechanical stability, are in balance (Busse et al., 2014; Emami et al., 1999; TRUST Investigators writing group et al., 2016), the LIPUS stimulation will, most likely, not have an additional effect. Furthermore, if an atrophic non-union is established and substantial biological inertness in bone is observed, the fracture deterioration might not be efficiently compensated for by mechanical stimulation with LIPUS (Malizos et al., 2006; Moghaddam et al., 2016; Watanabe et al., 2010). The exposure to micromotion generated by LIPUS (Greenleaf, 2003) might, however, be beneficial for fractures healing with a delay, where biological phenomena are still in place and LIPUS can help supporting the biomechanical environment (Leighton et al., 2017; Majeed et al., 2020; Watanabe et al., 2013). However, these hypotheses require further evaluation in valid in vitro and preclinical models, followed by clinical research.

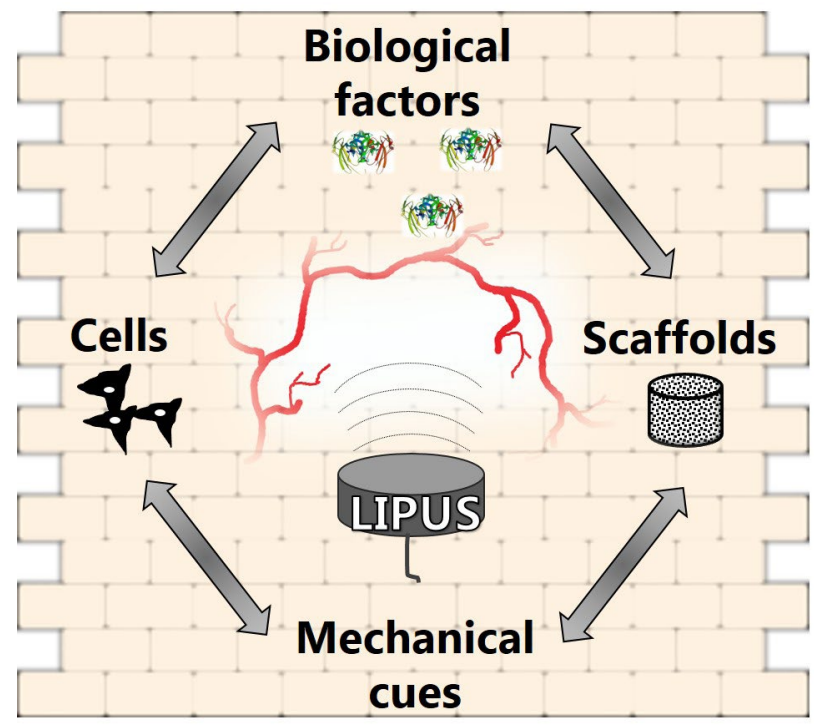

Fig. 4. Role of LIPUS with respect to the "diamond concept" of bone regeneration. Given the fracture stability, LIPUS stimulation might mimic the mechanical cues induced by interfragmentary motion, crucial for successful healing. 


\section{Conclusions}

The present review attempted to emphasise the limited knowledge on the principal mechanisms of the LIPUS technique and on the lack of adequate clinical evaluation. Research is needed to better understand the in vitro and in vivo biological and physical mechanisms involved, using set-ups ensuring an adequate translation of the optimal acoustic dose to the clinical setting. Conducting double-blind, randomised, placebo-controlled clinical trials is required for various bone fracture types (fresh, delayed- and non-union), in cast and fixed with implants, for large patient cohorts. Moreover, these studies should ideally be non-industry funded so as to eliminate potential bias. Clinical trials need to be supplied with regular follow-up appointments and easy access to communication with the medical personnel. Detailed documentation of patient compliance is needed, including the population that was intended to be treated originally, the individuals that followed the protocol properly, the number of days LIPUS was applied and the duration of treatment. It should also be specified whether the active minutes recorded by the LIPUS device were counted only when the probe was in direct skin contact. Additionally, investigation and optimisation of LIPUS-treatment protocols for fractures in aged individuals and patients with chronic metabolic disorders, where complementary methods could be used, is worth considering.

\section{Acknowledgements}

The authors would like to thank Ruslan Putc for producing the graphical abstract art work. RP acknowledges support by the Deutsche Forschungsgemeinschaft under the grant PU 701/1-1.

\section{References}

Adukia V, Al-Hubeshy Z, Mangwani J (2021) Can low intensity pulsed ultrasound (LIPUS) be used as an alternative to revision surgery for patients with non-unions following fracture fixation? J Clin Orthop Trauma 13: 147-155.

Akiyama H, Hachiya Y, Otsuka H, Kurisuno M, Kawanabe K, Katayama N, Ohura H, Yamamoto K, Sato K, Matsuda S (2014) Low-intensity pulsed ultrasound therapy stimulates callus formation between host femur and cortical onlay strut allograft. Ultrasound Med Biol 40: 1197-1203.

Anderson R, Parekh S, Braid-Forbes MJ, Steen RG (2019) Delayed healing in metatarsal fractures: role of low-intensity pulsed ultrasound treatment. J Foot Ankle Surg 58: 1145-1151.

Andrzejowski P, Giannoudis PV (2019) The 'diamond concept' for long bone non-union management. J Orthop Traumatol 20: 21. DOI: 10.1186/s10195-019-0528-0.

Antonova E, Le TK, Burge R, Mershon J (2013) Tibia shaft fractures: costly burden of nonunions. BMC Musculoskelet Disord 14: 42. DOI: 10.1186/14712474-14-42.

Aonuma H, Miyakoshi N, Kasukawa Y, Kamo K, Sasaki H, Tsuchie H, Segawa T, Shimada Y (2014) Effects of combined therapy of alendronate and lowintensity pulsed ultrasound on metaphyseal bone repair after osteotomy in the proximal tibia of aged rats. J Bone Miner Metab 32: 232-239.

Arima H, Suzuki Y, Togawa D, Mihara Y, Murata H, Matsuyama Y (2017) Low-intensity pulsed ultrasound is effective for progressive-stage lumbar spondylolysis with MRI high-signal change. Eur Spine J 26: 3122-3128.

Arimoto S, Hasegawa T, Takeda D, Tateishi C, Akashi M, Furudoi S, Komori T (2019) Effect of lowintensity pulsed ultrasound after intraoral vertical ramus osteotomy. Oral Surg Oral Med Oral Pathol Oral Radiol 128: 581-589.

Azuma Y, Ito M, Harada Y, Takagi H, Ohta T, Jingushi S (2001) Low-intensity pulsed ultrasound accelerates rat femoral fracture healing by acting on the various cellular reactions in the fracture callus. J Bone Miner Res 16: 671-680.

Bajada S, Marshall MJ, Wright KT, Richardson JB, Johnson WE (2009) Decreased osteogenesis, increased cell senescence and elevated Dickkopf-1 secretion in human fracture non union stromal cells. Bone 45: 726-735.

Bastian O, Pillay J, Alblas J, Leenen L, Koenderman L, Blokhuis T (2011) Systemic inflammation and fracture healing. J Leukoc Biol 89: 669-673.

Bawale R, Segmeister M, Sinha S, Shariff S, Singh B (2020) Experience of an isolated use of low-intensity pulsed ultrasound therapy on fracture healing in established non-unions: a prospective case series. J Ultrasound 24: 249-252.

Berber R, Aziz S, Simkins J, Lin SS, Mangwani J (2020) Low intensity pulsed ultrasound therapy (LIPUS): a review of evidence and potential applications in diabetics. J Clin Orthop Trauma 11: S500-S505.

Bhandari M, Fong K, Sprague S, Williams D, Petrisor B (2012) Variability in the definition and perceived causes of delayed unions and nonunions: a cross-sectional, multinational survey of orthopaedic surgeons. J Bone Joint Surg Am 94: e1091-1096.

Biglari B, Yildirim TM, Swing T, Bruckner T, Danner W, Moghaddam A (2016) Failed treatment of long bone nonunions with low intensity pulsed ultrasound. Arch Orthop Trauma Surg 136: 11211134.

Bishop JA, Palanca AA, Bellino MJ, Lowenberg DW (2012) Assessment of compromised fracture healing. J Am Acad Orthop Surg 20: 273-282.

Brand JC, Jr., Brindle T, Nyland J, Caborn DN, Johnson DL (1999) Does pulsed low intensity 
ultrasound allow early return to normal activities when treating stress fractures? A review of one tarsal navicular and eight tibial stress fractures. Iowa Orthop J 19: 26-30.

Busse JW, Bhandari M (2004) Therapeutic ultrasound and fracture healing: a survey of beliefs and practices. Arch Phys Med Rehabil 85: 1653-1656.

Busse JW, Bhandari M, Einhorn TA, Heckman JD, Leung KS, Schemitsch E, Tornetta P 3rd, Walter SD, Guyatt GH (2014) Trial to re-evaluate ultrasound in the treatment of tibial fractures (TRUST): a multicenter randomized pilot study. Trials 15: 206. DOI: 10.1186/1745-6215-15-206.

Carlson EJ, Save AV, Slade JF 3rd, Dodds SD (2015) Low-intensity pulsed ultrasound treatment for scaphoid fracture nonunions in adolescents. J Wrist Surg 4: 115-120.

Carter TG, Brar PS, Tolas A, Beirne OR (2008) Offlabel use of recombinant human bone morphogenetic protein-2 (rhBMP-2) for reconstruction of mandibular bone defects in humans. J Oral Maxillofac Surg 66: 1417-1425.

Carvalho DC, Cliquet Junior A (2004) The action of low-intensity pulsed ultrasound in bones of osteopenic rats. Artif Organs 28: 114-118.

Cauley JA (2017) Osteoporosis: fracture epidemiology update 2016. Curr Opin Rheumatol 29: 150-156.

Chen Z, Zhang Z, Feng J, Guo Y, Yu Y, Cui J, Li H, Shang L (2018) Influence of mussel-derived bioactive BMP-2-decorated PLA on MSC behavior in vitro and verification with osteogenicity at ectopic sites in vivo. ACS Appl Mater Interfaces 10: 11961-11971.

Chen Z, Zhang Z, Ma X, Duan Z, Hui J, Zhu C, Zhang D, Fan D, Shang L, Chen F (2019) Newly designed human-like collagen to maximize sensitive release of BMP-2 for remarkable repairing of bone defects. Biomolecules 9: 450. DOI: 10.3390/ biom 9090450 .

Claes L, Recknagel S, Ignatius A (2012) Fracture healing under healthy and inflammatory conditions. Nat Rev Rheumatol 8: 133-143.

Clark D, Nakamura M, Miclau T, Marcucio R (2017) Effects of aging on fracture healing. Curr Osteoporos Rep 15: 601-608.

Coles CP, Gross M (2000) Closed tibial shaft fractures: management and treatment complications. A review of the prospective literature. Can J Surg 43: 256-262.

Cook SD, Ryaby JP, McCabe J, Frey JJ, Heckman JD, Kristiansen TK (1997) Acceleration of tibia and distal radius fracture healing in patients who smoke. Clin Orthop Relat Res: 198-207.

Corrales LA, Morshed S, Bhandari M, Miclau $\mathrm{T}$ (2008) Variability in the assessment of fracturehealing in orthopaedic trauma studies. J Bone Joint Surg Am 90: 1862-1868.

Coughlin MJ, Simth BW, Traughber P (2008) The evaluation of the healing rate of subtalar arthrodeses, part 2: the effect of low-intensity ultrasound stimulation. Foot Ankle Int 29: 970-977.
Courtney PM, Bernstein J, Ahn J (2011) In brief: closed tibial shaft fractures. Clin Orthop Relat Res 469: 3518-3521.

Czobor P, Skolnick P (2011) The secrets of a successful clinical trial: compliance, compliance, and compliance. Mol Interv 11: 107-110.

D'Ippolito G, Schiller PC, Ricordi C, Roos BA, Howard GA (1999) Age-related osteogenic potential of mesenchymal stromal stem cells from human vertebral bone marrow. J Bone Miner Res 14: 11151122.

da Silva Junior EM, Mesquita-Ferrari RA, Franca CM, Andreo L, Bussadori SK, Fernandes KPS (2017) Modulating effect of low intensity pulsed ultrasound on the phenotype of inflammatory cells. Biomed Pharmacother 96: 1147-1153.

Ding ZC, Lin YK, Gan YK, Tang TT (2018) Molecular pathogenesis of fracture nonunion. J Orthop Translat 14: 45-56.

Duarte LR (1983) The stimulation of bone growth by ultrasound. Arch Orthop Trauma Surg 101: 153159.

Dudda M, Hauser J, Muhr G, Esenwein SA (2011) Low-intensity pulsed ultrasound as a useful adjuvant during distraction osteogenesis: a prospective, randomized controlled trial. J Trauma 71: 1376-1380.

El-Mowafi H, Mohsen M (2005) The effect of lowintensity pulsed ultrasound on callus maturation in tibial distraction osteogenesis. Int Orthop 29: 121-124.

Elvey MH, Miller R, Khor KS, Protopapa E, Horwitz MD, Hunter AR (2020) The use of lowintensity pulsed ultrasound in hand and wrist nonunions. J Plast Surg Hand Surg 54: 101-106.

Emami A, Petren-Mallmin M, Larsson S (1999) No effect of low-intensity ultrasound on healing time of intramedullary fixed tibial fractures. J Orthop Trauma 13: 252-257.

Fajardo M, Liu CJ, Egol K (2009) Levels of expression for BMP-7 and several BMP antagonists may play an integral role in a fracture nonunion: a pilot study. Clin Orthop Relat Res 467: 3071-3078.

Farkash U, Bain O, Gam A, Nyska M, Sagiv P (2015) Low-intensity pulsed ultrasound for treating delayed union scaphoid fractures: case series. J Orthop Surg Res 10: 72. DOI: 10.1186/s13018-015-0221-9.

Fernandez DL (2005) Closed manipulation and casting of distal radius fractures. Hand Clin 21: 307316.

Ferreri SL, Talish R, Trandafir T, Qin YX (2011) Mitigation of bone loss with ultrasound induced dynamic mechanical signals in an OVX induced rat model of osteopenia. Bone 48: 1095-1102.

Filipowska J, Tomaszewski KA, Niedzwiedzki L, Walocha JA, Niedzwiedzki T (2017) The role of vasculature in bone development, regeneration and proper systemic functioning. Angiogenesis 20: 291302.

Gan TY, Kuah DE, Graham KS, Markson G (2014) Low-intensity pulsed ultrasound in lower limb bone stress injuries: a randomized controlled trial. Clin J Sport Med 24: 457-460. 
Garner MR (2017) In patients with a tibial fracture, low-intensity pulsed ultrasound after intramedullary nail fixation did not accelerate radiographic healing or improve functional recovery. J Bone Joint Surg Am 99: 1394. DOI: 10.2106/JBJS.17.00554.

Gebauer D, Correll J (2005) Pulsed low-intensity ultrasound: a new salvage procedure for delayed unions and nonunions after leg lengthening in children. J Pediatr Orthop 25: 750-754.

Gebauer D, Mayr E, Orthner E, Ryaby JP (2005) Low-intensity pulsed ultrasound: effects on nonunions. Ultrasound Med Biol 31: 1391-1402.

Giannoudis PV, Einhorn TA, Marsh D (2007) Fracture healing: the diamond concept. Injury 38 Suppl 4: S3-6.

Gleizal A, Li S, Pialat JB, Beziat JL (2006) Transcriptional expression of calvarial bone after treatment with low-intensity ultrasound: an in vitro study. Ultrasound Med Biol 32: 1569-1574.

Gold SM, Wasserman R (2005) Preliminary results of tibial bone transports with pulsed low intensity ultrasound (Exogen). J Orthop Trauma 19: 10-16.

Gopalan A, Panneerselvam E, Doss GT, Ponvel K, Raja Vb K (2020) Evaluation of efficacy of low intensity pulsed ultrasound in facilitating mandibular fracture healing-a blinded randomized controlled clinical trial. J Oral Maxillofac Surg 78: 997.e1-997.e7.

Govender S, Csimma C, Genant HK, ValentinOpran A, Amit Y, Arbel R, Aro H, Atar D, Bishay M, Borner MG, Chiron P, Choong P, Cinats J, Courtenay B, Feibel R, Geulette B, Gravel C, Haas N, Raschke M, Hammacher E, van der Velde D, Hardy P, Holt M, Josten C, Ketterl RL, Lindeque B, Lob G, Mathevon H, McCoy G, Marsh D, Miller R, Munting E, Oevre S, Nordsletten L, Patel A, Pohl A, Rennie W, Reynders P, Rommens PM, Rondia J, Rossouw WC, Daneel PJ, Ruff S, Ruter A, Santavirta S, Schildhauer TA, Gekle C, Schnettler R, Segal D, Seiler H, Snowdowne RB, Stapert J, Taglang G, Verdonk R, Vogels L, Weckbach A, Wentzensen A, Wisniewski T, BMP-2 Evaluation in Surgery for Tibial Trauma (BESTT) Study Group (2002) Recombinant human bone morphogenetic protein-2 for treatment of open tibial fractures: a prospective, controlled, randomized study of four hundred and fifty patients. J Bone Joint Surg Am 84: 2123-2134.

Greenleaf JF, Kinnick, R., Bolander, M. (2003) Ultrasonically induced motion in tissue during fracture treatment? Ultrasound Med Biol 29: S157-S158.

Griffin XL (2016) Low intensity pulsed ultrasound for fractures of the tibial shaft. BMJ 355: i5652. DOI: 10.1136/bmj.i5652.

Griffin XL, Parsons N, Costa ML, Metcalfe D (2014) Ultrasound and shockwave therapy for acute fractures in adults. Cochrane Database Syst Rev 2014: CD008579. DOI: 10.1002/14651858.CD008579.pub3.

Grundnes O, Reikeras O (1993a) The importance of the hematoma for fracture healing in rats. Acta Orthop Scand 64: 340-342.
Grundnes O, Reikeras O (1993b) The role of hematoma and periosteal sealing for fracture healing in rats. Acta Orthop Scand 64: 47-49.

Gurevitch O, Slavin S, Feldman AG (2007) Conversion of red bone marrow into yellow - cause and mechanisms. Med Hypotheses 69: 531-536.

Haffner-Luntzer M, Liedert A, Ignatius A (2016) Mechanobiology of bone remodeling and fracture healing in the aged organism. Innov Surg Sci 1: 57-63.

Hak DJ, Fitzpatrick D, Bishop JA, Marsh JL, Tilp S, Schnettler R, Simpson H, Alt V (2014) Delayed union and nonunions: epidemiology, clinical issues, and financial aspects. Injury 45 Suppl 2: S3-7.

Handolin L, Kiljunen V, Arnala I, Kiuru MJ, Pajarinen J, Partio EK, Rokkanen P (2005a) Effect of ultrasound therapy on fractures of the ankle joint fixed bone healing of lateral malleolar with bioabsorbable screws. J Orthop Sci 10: 391-395.

Handolin L, Kiljunen V, Arnala I, Pajarinen J, Partio EK, Rokkanen P (2005b) The effect of low intensity ultrasound and bioabsorbable self-reinforced polyL-lactide screw fixation on bone in lateral malleolar fractures. Arch Orthop Trauma Surg 125: 317-321.

Hardy R, Cooper MS (2009) Bone loss in inflammatory disorders. J Endocrinol 201: 309-320.

Harrison A, Lin S, Pounder N, Mikuni-Takagaki Y (2016) Mode \& mechanism of low intensity pulsed ultrasound (LIPUS) in fracture repair. Ultrasonics 70: 45-52.

Harwood PJN, J. B.; Michael, A. L. R. (2010) (ii) An update on fracture healing and non-union. Orthopaedics Trauma 24: 9-23.

Hauser RA, Lackner JB, Steilen-Matias D, Harris DK (2016) A systematic review of dextrose prolotherapy for chronic musculoskeletal pain. Clin Med Insights Arthritis Musculoskelet Disord 9: 139159.

Healy WL, Jupiter JB, Kristiansen TK, White RR (1990) Nonunion of the proximal humerus. A review of 25 cases. J Orthop Trauma 4: 424-431.

Heckman JD (2017) Invited commentary related to: when is a fracture not "fresh"? Aligning reimbursement with patient outcome after treatment with low-intensity pulsed ultrasound. J Orthop Trauma 31: 251. DOI: 10.1097/BOT.0000000000000808.

Heckman JD, Ryaby JP, McCabe J, Frey JJ, Kilcoyne RF (1994) Acceleration of tibial fracture-healing by non-invasive, low-intensity pulsed ultrasound. J Bone Joint Surg Am 76: 26-34.

Heckman JD, Sarasohn-Kahn J (1997) The economics of treating tibia fractures. The cost of delayed unions. Bull Hosp Jt Dis 56: 63-72.

Hemery X, Ohl X, Saddiki R, Barresi L, Dehoux E (2011) Low-intensity pulsed ultrasound for nonunion treatment: a 14-case series evaluation. Orthop Traumatol Surg Res 97: 51-57.

Hemmatian H, Bakker AD, Klein-Nulend J, van Lenthe GH (2017) Aging, osteocytes, and mechanotransduction. Curr Osteoporos Rep 15: 401411. 
Hensel K, Mienkina MP, Schmitz G (2011) Analysis of ultrasound fields in cell culture wells for in vitro ultrasound therapy experiments. Ultrasound Med Biol 37: 2105-2115.

Horne DA, Jones PD, Adams MS, Lotz JC, Diederich CJ (2020) LIPUS far-field exposimetry system for uniform stimulation of tissues in vitro: development and validation with bovine intervertebral disc cells. Biomed Phys Eng Express 6: 035033. DOI: 10.1088/2057-1976/ab8b26.

Hou $\mathrm{CH}$, Lin J, Huang SC, Hou SM, Tang CH (2009) Ultrasound stimulates NF-kappaB activation and iNOS expression via the Ras/Raf/MEK/ERK signaling pathway in cultured preosteoblasts. J Cell Physiol 220: 196-203.

Hwang DY, On SW, Song SI (2016) Bone regenerative effect of recombinant human bone morphogenetic protein-2 after cyst enucleation. Maxillofac Plast Reconstr Surg 38: 22. DOI: 10.1186/ s40902-016-0070-4.

Hyun SJ, Han DK, Choi SH, Chai JK, Cho KS, Kim CK, Kim CS (2005) Effect of recombinant human bone morphogenetic protein-2, -4 , and -7 on bone formation in rat calvarial defects. J Periodontol 76: 1667-1674.

Iwakura T, Miwa M, Sakai Y, Niikura T, Lee SY, Oe K, Hasegawa T, Kuroda R, Fujioka H, Doita M, Kurosaka M (2009) Human hypertrophic nonunion tissue contains mesenchymal progenitor cells with multilineage capacity in vitro. J Orthop Res 27: 208215.

Javaheri B, Pitsillides AA (2019) Aging and mechanoadaptive responsiveness of bone. Curr Osteoporos Rep 17: 560-569.

Jones CP, Coughlin MJ, Shurnas PS (2006) Prospective CT scan evaluation of hindfoot nonunions treated with revision surgery and low-intensity ultrasound stimulation. Foot Ankle Int 27: 229-235.

Kasper G, Mao L, Geissler S, Draycheva A, Trippens J, Kuhnisch J, Tschirschmann M, Kaspar K, Perka C, Duda GN, Klose J (2009) Insights into mesenchymal stem cell aging: involvement of antioxidant defense and actin cytoskeleton. Stem Cells 27: 1288-1297.

Kasturi G, Adler RA (2011a) Mechanical means to improve bone strength: ultrasound and vibration. Curr Rheumatol Rep 13: 251-256.

Kasturi GC, Adler RA (2011b) Osteoporosis: nonpharmacologic management. PM R 3: 562-572.

Katano M, Naruse K, Uchida K, Mikuni-Takagaki Y, Takaso M, Itoman M, Urabe K (2011) Low intensity pulsed ultrasound accelerates delayed healing process by reducing the time required for the completion of endochondral ossification in the aged mouse femur fracture model. Exp Anim 60: 385-395.

Kim HK, Oxendine I, Kamiya N (2013) Highconcentration of BMP2 reduces cell proliferation and increases apoptosis via DKK1 and SOST in human primary periosteal cells. Bone 54: 141-150.

Kinami Y, Noda T, Ozaki T (2013) Efficacy of lowintensity pulsed ultrasound treatment for surgically managed fresh diaphyseal fractures of the lower extremity: multi-center retrospective cohort study. J Orthop Sci 18: 410-418.

Klein-Nulend J, van Oers RF, Bakker AD, Bacabac RG (2014) Nitric oxide signaling in mechanical adaptation of bone. Osteoporos Int 25: 1427-1437.

Kloen P, Doty SB, Gordon E, Rubel IF, Goumans MJ, Helfet DL (2002) Expression and activation of the BMP-signaling components in human fracture nonunions. J Bone Joint Surg Am 84: 1909-1918.

Koga T, Lee SY, Niikura T, Koh A, Dogaki Y, Okumachi E, Akisue T, Kuroda R, Kurosaka M (2013) Effect of low-intensity pulsed ultrasound on bone morphogenetic protein 7-induced osteogenic differentiation of human nonunion tissue-derived cells in vitro. J Ultrasound Med 32: 915-922.

Koolen M, Longoni A, van der Stok J, Van der Jagt O, Gawlitta D, Weinans H (2019) Complete regeneration of large bone defects in rats with commercially available fibrin loaded with BMP-2. Eur Cell Mater 38: 94-105.

Krishnan V, Bryant HU, Macdougald OA (2006) Regulation of bone mass by Wnt signaling. J Clin Invest 116: 1202-1209.

Kristiansen TK, Ryaby JP, McCabe J, Frey JJ, Roe LR (1997) Accelerated healing of distal radial fractures with the use of specific, low-intensity ultrasound. A multicenter, prospective, randomized, double-blind, placebo-controlled study. J Bone Joint Surg Am 79: 961-973.

Kwong FN, Hoyland JA, Evans CH, Freemont AJ (2009a) Regional and cellular localisation of BMPs and their inhibitors' expression in human fractures. Int Orthop 33: 281-288.

Kwong FN, Hoyland JA, Freemont AJ, Evans CH (2009b) Altered relative expression of BMPs and BMP inhibitors in cartilaginous areas of human fractures progressing towards nonunion. J Orthop Res 27: 752757.

Lai CL, Tseng SY, Chen CN, Liao WC, Wang CH, Lee MC, Hsu PS (2013) Effect of 6 months of whole body vibration on lumbar spine bone density in postmenopausal women: a randomized controlled trial. Clin Interv Aging 8: 1603-1609.

Lancerotto L, Orgill DP (2014) Mechanoregulation of angiogenesis in wound healing. Adv Wound Care (New Rochelle) 3: 626-634.

Leighton R, Watson JT, Giannoudis P, Papakostidis C, Harrison A, Steen RG (2017) Healing of fracture nonunions treated with low-intensity pulsed ultrasound (LIPUS): a systematic review and metaanalysis. Injury 48: 1339-1347.

Leng Y, Yang F, Wang Q, Li Z, Yuan B, Peng C, Ren G, Wang Z, Cui Y, Wang Y, Zhu L, Liu H, Wu D (2019) Material-based therapy for bone nonunion. Materials Design 183: 108161. DOI: 10.1016/j. matdes.2019.108161.

Lerner A, Stein H, Soudry M (2004) Compound high-energy limb fractures with delayed union: our experience with adjuvant ultrasound stimulation (exogen). Ultrasonics 42: 915-917. 
Lerner RK, Esterhai JL Jr, Polomano RC, Cheatle MD, Heppenstall RB (1993) Quality of life assessment of patients with posttraumatic fracture nonunion, chronic refractory osteomyelitis, and lower-extremity amputation. Clin Orthop Relat Res: 28-36.

Leskinen JJ, Hynynen K (2012) Study of factors affecting the magnitude and nature of ultrasound exposure with in vitro set-ups. Ultrasound Med Biol 38: 777-794.

Leung KS, Lee WS, Cheung WH, Qin L (2004a) Lack of efficacy of low-intensity pulsed ultrasound on prevention of postmenopausal bone loss evaluated at the distal radius in older Chinese women. Clin Orthop Relat Res: 234-240. DOI: 10.1097/01. blo.0000137557.59228.4d.

Leung KS, Lee WS, Tsui HF, Liu PP, Cheung WH (2004b) Complex tibial fracture outcomes following treatment with low-intensity pulsed ultrasound. Ultrasound Med Biol 30: 389-395.

Li JK, Chang WH, Lin JC, Ruaan RC, Liu HC, Sun JS (2003) Cytokine release from osteoblasts in response to ultrasound stimulation. Biomaterials 24: 2379-2385.

Li X, Li X, Lin J, Sun X, Ding Q (2019) Exosomes derived from low-intensity pulsed ultrasoundtreated dendritic cells suppress tumor necrosis factorinduced endothelial inflammation. J Ultrasound Med 38: 2081-2091.

Liu YW, Wei XE, Kuang Y, Zheng YX, Gu XF, Zhan HS, Shi YY (2014) Ultrasound treatment for accelerating fracture healing of the distal radius. A control study. Acta Cir Bras 29: 765-770.

Loi F, Cordova LA, Pajarinen J, Lin TH, Yao Z, Goodman SB (2016) Inflammation, fracture and bone repair. Bone 86: 119-130.

Lubbert PH, van der Rijt RH, Hoorntje LE, van der Werken C (2008) Low-intensity pulsed ultrasound (LIPUS) in fresh clavicle fractures: a multi-centre double blind randomised controlled trial. Injury 39: 1444-1452.

Majeed H, Karim T, Davenport J, Karski M, Smith R, Clough TM (2020) Clinical and patient-reported outcomes following low intensity pulsed ultrasound (LIPUS, Exogen) for established post-traumatic and post-surgical nonunion in the foot and ankle. Foot Ankle Surg 26: 405-411.

Malizos KN, Hantes ME, Protopappas V, Papachristos A (2006) Low-intensity pulsed ultrasound for bone healing: an overview. Injury 37 Suppl 1: S56-62.

Marsell R, Einhorn TA (2011) The biology of fracture healing. Injury 42: 551-555.

Matsubara TSM, Morioka S, Aoki K, Shimizu T, Ide K, Nanba M, Hagiwara K, Okabayashi R (2015) Compliance of low-intensity pulsed ultrasound (LIPUS) for fresh fractures. J Orthop Trauma 29: S3. DOI: 10.1097/01.bot.0000462956.71988.b6-

Maurya RK, Jayan B, Singh H, Nakra O, Sharma P (2019) Effects of low-intensity pulsed ultrasound therapy on the temporomandibular joint complex in conjunction with a fixed functional appliance: a prospective 3-dimensional cone beam computed tomographic study. J Ultrasound Med 38: 1661-1676.

Mayr E, Frankel V, Rüter A (2000) Ultrasoundan alternative healing method for nonunions? Arch Orthop Trauma Surg 120: 1-8.

Mitchell SAT, Majuta LA, Mantyh PW (2018) New insights in understanding and treating bone fracture pain. Curr Osteoporos Rep 16: 325-332.

Moghaddam A, Yildirim TM, Westhauser F, Danner W, Swing T, Bruckner T, Biglari B (2016) Low intensity pulsed ultrasound in the treatment of long bone nonunions: evaluation of cytokine expression as a tool for objectifying nonunion therapy. J Orthop 13: 306-312.

Moher D, Liberati A, Tetzlaff J, Altman DG, PRISMA Group (2009) Preferred reporting items for systematic reviews and meta-analyses: the PRISMA statement. PLoS Med 6: e1000097. DOI: 10.1371/ journal.pmed.1000097.

Mortazavi S, Mortazavi S, Paknahad M (2016) Mode \& mechanism of low intensity pulsed ultrasound (LIPUS) in fracture repair. Ultrasonics 71: 142. DOI: 10.1016/j.ultras.2016.06.006.

Nakao J, Fujii Y, Kusuyama J, Bandow K, Kakimoto K, Ohnishi T, Matsuguchi T (2014) Lowintensity pulsed ultrasound (LIPUS) inhibits LPSinduced inflammatory responses of osteoblasts through TLR4-MyD88 dissociation. Bone 58: 17-25.

Namera MO, Mahmoud G, Abdulhadi A, Burhan A (2020) Effects of low-intensity pulsed ultrasound (LIPUS) applied on the temporomandibular joint (TMJ) region on the functional treatment of class II malocclusion: a randomized controlled trial. Den Med Probl 57: 53-60.

Nauth A, Lee M, Gardner MJ, Brinker MR, Warner SJ, Tornetta P, 3rd, Leucht P (2018) Principles of nonunion management: state of the art. J Orthop Trauma 32 Suppl 1: S52-S57.

Ning H WX, Wu Q, Yu W, Wang H, Zheng S, Chen Y, Li Y and Su J (2019) Microfiber-reinforced composite hydrogels loaded with rat adipose-derived stem cells and BMP-2 for the treatment of medicationrelated osteonecrosis of the jaw in a rat model. ACS Biomat Sci Eng 5: 2430-2443.

Nolte P, Anderson R, Strauss E, Wang Z, Hu L, Xu Z, Steen RG (2016) Heal rate of metatarsal fractures: a propensity-matching study of patients treated with low-intensity pulsed ultrasound (LIPUS) vs. surgical and other treatments. Injury 47: 2584-2590.

Nolte PA, van der Krans A, Patka P, Janssen IM, Ryaby JP, Albers GH (2001) Low-intensity pulsed ultrasound in the treatment of nonunions. J Trauma 51: 693-702.

Olkku A, Leskinen JJ, Lammi MJ, Hynynen K, Mahonen A (2010) Ultrasound-induced activation of Wnt signaling in human MG-63 osteoblastic cells. Bone 47: 320-330.

Ortega N, Behonick D, Stickens D, Werb Z (2003) How proteases regulate bone morphogenesis. Ann N Y Acad Sci 995: 109-116. 
Ota T, Itoh S, Matsuyama Y (2018) Comparison of treatment results for mallet finger fractures in children between low-intensity pulsed ultrasound stimulation and Ishiguro's method. Hand (N Y) 13: 80-85.

Ota T, Itoh S, Yamashita K (2017) The efficacy and safety of combination therapy of low-intensity pulsed ultrasound stimulation in the treatment of unstable both radius and ulna fractures in children. Biomed Mater Eng 28: 545-553.

Ozdemir F, Zateri C, Murat S (2008) Evaluation of the efficacy of therapeutic ultrasound on bone mineral density in postmenopausal period. Rheumatol Int 28: 361-365.

Özkan S, Nolte PA, Van Den Bekerom MPJ, Bloemers FW (2019) Diagnosis and management of long-bone nonunions: a nationwide survey. Eur J Trauma Emerg Surg 45: 3-11.

Padilla F, Puts R, Vico L, Guignandon A, Raum K (2016) Stimulation of bone repair with ultrasound. Adv Exp Med Biol 880: 385-427.

Padilla F, Puts R, Vico L, Raum K (2014) Stimulation of bone repair with ultrasound: a review of the possible mechanic effects. Ultrasonics 54: 11251145.

Park SH, Silva M, Bahk WJ, McKellop H, Lieberman JR (2002) Effect of repeated irrigation and debridement on fracture healing in an animal model. J Orthop Res 20: 1197-1204.

Patel K, Kumar S, Kathiriya N, Madan S, Shah A, Venkataraghavan K, Jani M (2015) An evaluation of the effect of therapeutic ultrasound on healing of mandibular fracture. Craniomaxillofac Trauma Reconstr 8: 299-306.

Perren SM (2002) Evolution of the internal fixation of long bone fractures. The scientific basis of biological internal fixation: choosing a new balance between stability and biology. J Bone Joint Surg Br 84: 1093-1110.

Pilla AA, Mont MA, Nasser PR, Khan SA, Figueiredo M, Kaufman JJ, Siffert RS (1990) Noninvasive low-intensity pulsed ultrasound accelerates bone healing in the rabbit. J Orthop Trauma 4: 246253.

Pinzone JJ, Hall BM, Thudi NK, Vonau M, Qiang YW, Rosol TJ, Shaughnessy JD Jr (2009) The role of Dickkopf-1 in bone development, homeostasis, and disease. Blood 113: 517-525.

Polguj M, Blizniewska K, Jedrzejewski K, Majos A, Topol M (2013) Morphological study of linea aspera variations - proposal of classification and sexual dimorphism. Folia Morphol (Warsz) 72: 72-77.

Poolman RW, Agoritsas T, Siemieniuk RA, Harris IA, Schipper IB, Mollon B, Smith M, Albin A, Nador S, Sasges W, Schandelmaier S, Lytvyn L, Kuijpers T, van Beers LW, Verhofstad MH, Vandvik PO (2017) Low intensity pulsed ultrasound (LIPUS) for bone healing: a clinical practice guideline. BMJ 356: j576. DOI: $10.1136 / \mathrm{bmj} . j 576$.

Pounder NM, Harrison AJ (2008) Low intensity pulsed ultrasound for fracture healing: a review of the clinical evidence and the associated biological mechanism of action. Ultrasonics 48: 330-338.

Pounder NM, Jones JT, Tanis KJ (2016) Design evolution enhances patient compliance for lowintensity pulsed ultrasound device usage. Med Devices (Auckl) 9: 423-427.

Prodinger PM, Burklein D, Foehr P, Kreutzer K, Pilge H, Schmitt A, Eisenhart-Rothe RV, Burgkart $\mathrm{R}$, Bissinger $\mathrm{O}$, Tischer $\mathrm{T}$ (2018) Improving results in rat fracture models: enhancing the efficacy of biomechanical testing by a modification of the experimental setup. BMC Musculoskelet Disord 19: 243. DOI: 10.1186/s12891-018-2155-y.

Pullar T, Kumar S, Feely M (1989) Compliance in clinical trials. Ann Rheum Dis 48: 871-875.

Puts R, Albers J, Kadow-Romacker A, Geissler S, Raum K (2016a) Influence of donor age and stimulation intensity on osteogenic differentiation of rat mesenchymal stromal cells in response to focused low-intensity pulsed ultrasound. Ultrasound Med Biol 42: 2965-2974.

Puts R, Ruschke K, Ambrosi TH, KadowRomacker A, Knaus P, Jenderka KV, Raum K (2016b) A focused low-intensity pulsed ultrasound (FLIPUS) system for cell stimulation: physical and biological proof of principle. IEEE Trans Ultrason Ferroelectr Freq Control 63: 91-100.

Raza H, Major P, Dederich D, El-Bialy T (2016) Effect of low-intensity pulsed ultrasound on orthodontically induced root resorption caused by torque: a prospective, double-blind, controlled clinical trial. Angle Orthod 86: 550-557.

Rohrbach D, Preininger B, Hesse B, Gerigk H, Perka C, Raum K (2013) The early phases of bone healing can be differentiated in a rat osteotomy model by focused transverse-transmission ultrasound. Ultrasound Med Biol 39: 1642-1653.

Ross SE, Hemati N, Longo KA, Bennett CN, Lucas PC, Erickson RL, MacDougald OA (2000) Inhibition of adipogenesis by Wnt signaling. Science 289: 950-953.

Roussignol X, Currey C, Duparc F, Dujardin $F$ (2012) Indications and results for the Exogen ultrasound system in the management of non-union: a 59-case pilot study. Orthop Traumatol Surg Res 98: 206-213.

Rubin C, Recker R, Cullen D, Ryaby J, McCabe J, McLeod K (2004) Prevention of postmenopausal bone loss by a low-magnitude, high-frequency mechanical stimuli: a clinical trial assessing compliance, efficacy, and safety. J Bone Miner Res 19: 343-351.

Rutten S, Nolte PA, Guit GL, Bouman DE, Albers GH (2007) Use of low-intensity pulsed ultrasound for posttraumatic nonunions of the tibia: a review of patients treated in the Netherlands. J Trauma 62: 902-908.

Rutten S, Nolte PA, Korstjens CM, Klein-Nulend J (2009) Low-intensity pulsed ultrasound affects RUNX2 immunopositive osteogenic cells in delayed clinical fracture healing. Bone 45: 862-869.

Rutten S, Nolte PA, Korstjens CM, van Duin MA, Klein-Nulend J (2008) Low-intensity pulsed 
ultrasound increases bone volume, osteoid thickness and mineral apposition rate in the area of fracture healing in patients with a delayed union of the osteotomized fibula. Bone 43: 348-354.

Salem KH, Schmelz A (2014) Low-intensity pulsed ultrasound shortens the treatment time in tibial distraction osteogenesis. Int Orthop 38: 1477-1482.

Santana-Rodríguez N, Clavo B, Llontop P, Fiuza MD, Calatayud-Gastardi J, López D, LópezFernández D, Aguiar-Santana IA, Ayub A, Alshehri K, Jordi NA, Zubeldia J, Bröering DC (2019) Pulsed ultrasounds reduce pain and disability, increasing rib fracture healing, in a randomized controlled trial. Pain Med 20: 1980-1988.

Schandelmaier S, Kaushal A, Lytvyn L, HeelsAnsdell D, Siemieniuk RA, Agoritsas T, Guyatt GH, Vandvik PO, Couban R, Mollon B, Busse JW (2017a) Low intensity pulsed ultrasound for bone healing: systematic review of randomized controlled trials. BMJ 356: j656. DOI: 10.1136/bmj.j656.

Schandelmaier S, Siemieniuk RA, Agoritsas T, Vandvik PO, Guyatt GH, Busse JW (2017b) Authors' reply to Farrar. BMJ 356: j1483. DOI: $10.1136 / \mathrm{bmj}$. j1483.

Schlundt C, Bucher CH, Tsitsilonis S, Schell H, Duda GN, Schmidt-Bleek K (2018) Clinical and research approaches to treat non-union fracture. Curr Osteoporos Rep 16: 155-168.

Schmal H, Brix M, Bue M, Ekman A, Ferreira N, Gottlieb H, Kold S, Taylor A, Toft Tengberg P, Ban I, Danish Orthopaedic Trauma S (2020) Nonunion consensus from the 4th annual meeting of the Danish Orthopaedic Trauma Society. EFORT Open Rev 5: 46-57.

Schmidt AH, Finkemeier CG, Tornetta P 3rd (2003) Treatment of closed tibial fractures. Instr Course Lect 52: 607-622.

Schofer MD, Block JE, Aigner J, Schmelz A (2010) Improved healing response in delayed unions of the tibia with low-intensity pulsed ultrasound: results of a randomized sham-controlled trial. BMC Musculoskelet Disord 11: 229. DOI: 10.1186/14712474-11-229.

Seong YJ, Song EH, Park C, Lee H, Kang IG, Kim HE, Jeong SH (2020) Porous calcium phosphatecollagen composite microspheres for effective growth factor delivery and bone tissue regeneration. Mater Sci Eng C Mater Biol Appl 109: 110480. DOI: 10.1016/j. msec.2019.110480.

Shakouri K, Eftekharsadat B, Oskuie MR, Soleimanpour J, Tarzamni MK, Salekzamani Y, Hoshyar Y, Nezami N (2010) Effect of low-intensity pulsed ultrasound on fracture callus mineral density and flexural strength in rabbit tibial fresh fracture. J Orthop Sci 15: 240-244.

Simpson AH, Keenan G, Nayagam S, Atkins RM, Marsh D, Clement ND (2017) Low-intensity pulsed ultrasound does not influence bone healing by distraction osteogenesis: a multicentre double-blind randomised control trial. Bone Joint J 99-B: 494-502.
Song MH, Kim TJ, Kang SH, Song HR (2019) Low-intensity pulsed ultrasound enhances callus consolidation in distraction osteogenesis of the tibia by the technique of lengthening over the nail procedure. BMC Musculoskelet Disord 20: 108. DOI: 10.1186/s12891-019-2490-7.

Stewart SK (2019) Fracture non-union: a review of clinical challenges and future research needs. Malays Orthop J 13: 1-10.

Subramanian A, Turner JA, Budhiraja G, Guha Thakurta S, Whitney NP, Nudurupati SS (2013) Ultrasonic bioreactor as a platform for studying cellular response. Tissue Eng Part C Methods 19: 244-255.

Suzuki A, Takayama T, Suzuki N, Kojima T, Ota N, Asano S, Ito K (2009a) Daily low-intensity pulsed ultrasound stimulates production of bone morphogenetic protein in ROS 17/2.8 cells. J Oral Sci 51: 29-36.

Suzuki A, Takayama T, Suzuki N, Sato M, Fukuda T, Ito K (2009b) Daily low-intensity pulsed ultrasound-mediated osteogenic differentiation in rat osteoblasts. Acta Biochim Biophys Sin (Shanghai) 41: 108-115.

Takikawa S, Matsui N, Kokubu T, Tsunoda M, Fujioka H, Mizuno K, Azuma Y (2001) Low-intensity pulsed ultrasound initiates bone healing in rat nonunion fracture model. J Ultrasound Med 20: 197205.

Tarride JE, Hopkins RB, Blackhouse G, Burke N, Bhandari M, Johal H, Guyatt GH, Busse JW (2017) Low-intensity pulsed ultrasound for treatment of tibial fractures: an economic evaluation of the TRUST study. Bone Joint J 99-B: 1526-1532.

Teoh KH, Whitham R, Wong JF, Hariharan K (2018) The use of low-intensity pulsed ultrasound in treating delayed union of fifth metatarsal fractures. Foot (Edinb) 35: 52-55.

TRUST Investigators writing group, Busse JW, Bhandari M, Einhorn TA, Schemitsch E, Heckman JD, Tornetta P 3rd, Leung KS, Heels-Ansdell D, MakossoKallyth S, Della Rocca GJ, Jones CB, Guyatt GH (2016) Re-evaluation of low intensity pulsed ultrasound in treatment of tibial fractures (TRUST): randomized clinical trial. BMJ 355: i5351. DOI: 10.1136/bmj.i5351.

Tsumaki N, Kakiuchi M, Sasaki J, Ochi T, Yoshikawa H (2004) Low-intensity pulsed ultrasound accelerates maturation of callus in patients treated with opening-wedge high tibial osteotomy by hemicallotasis. J Bone Joint Surg Am 86: 2399-2405.

Unsworth J, Kaneez S, Harris S, Ridgway J, Fenwick S, Chenery D, Harrison A (2007) Pulsed low intensity ultrasound enhances mineralisation in preosteoblast cells. Ultrasound Med Biol 33: 14681474.

Urita A, Iwasaki N, Kondo M, Nishio Y, Kamishima T, Minami A (2013) Effect of low-intensity pulsed ultrasound on bone healing at osteotomy sites after forearm bone shortening. J Hand Surg Am 38: 498503. 
Verschueren SM, Roelants M, Delecluse C, Swinnen S, Vanderschueren D, Boonen S (2004) Effect of 6-month whole body vibration training on hip density, muscle strength, and postural control in postmenopausal women: a randomized controlled pilot study. J Bone Miner Res 19: 352-359.

Volpin G, Shtarker, H. (2014) Management of delayed union, non-union and mal-union of long bone fractures. In: European Surgical Orthopaedics and Traumatology. Editor: Bentley G. pp: 241-266. DOI: 10.1007/978-3-642-34746-7_10.

Volpon JB, Mota FC, Beletti ME (2010) Lowintensity ultrasound application in distal radius metaphyseal bone defects of dogs. Ultrasound Med Biol 36: 1849-1855.

Wang FS, Kuo YR, Wang CJ, Yang KD, Chang PR, Huang YT, Huang HC, Sun YC, Yang YJ, Chen YJ (2004) Nitric oxide mediates ultrasound-induced hypoxia-inducible factor-1alpha activation and vascular endothelial growth factor-A expression in human osteoblasts. Bone 35: 114-123.

Wang SJ, Lewallen DG, Bolander ME, Chao EY, Ilstrup DM, Greenleaf JF (1994) Low intensity ultrasound treatment increases strength in a rat femoral fracture model. J Orthop Res 12: 40-47.

Warden SJ (2003) A new direction for ultrasound therapy in sports medicine. Sports Med 33: 95-107.

Warden SJ, Bennell KL, Matthews B, Brown DJ, McMeeken JM, Wark JD (2001) Efficacy of lowintensity pulsed ultrasound in the prevention of osteoporosis following spinal cord injury. Bone 29: 431-436.

Warden SJ, Wong WT, Bennell KL, McMeeken JM, Wark JD (2000) Facilitation of fracture repair using low-intensity pulsed ultrasound. Vet Comp Orthop Traumatol 13: 158-164.

Watanabe Y, Arai Y, Takenaka N, Kobayashi M, Matsushita T (2013) Three key factors affecting treatment results of low-intensity pulsed ultrasound for delayed unions and nonunions: instability, gap size, and atrophic nonunion. J Orthop Sci 18: 803-810.

Watanabe Y, Matsushita T, Bhandari M, Zdero R, Schemitsch EH (2010) Ultrasound for fracture healing: current evidence. J Orthop Trauma 24 Suppl 1: S56-61.

Wijnands KA, Brink PR, Weijers PH, Dejong CH, Poeze M (2012) Impaired fracture healing associated with amino acid disturbances. Am J Clin Nutr 95: 1270-1277.

Wu S, Kawahara Y, Manabe T, Ogawa K, Matsumoto M, Sasaki A, Yuge L (2009) Lowintensity pulsed ultrasound accelerates osteoblast differentiation and promotes bone formation in an osteoporosis rat model. Pathobiology 76: 99-107.

Yadollahpour A, Rashidi S (2017) Therapeutic applications of low-intensity pulsed ultrasound in osteoporosis. Asian J Pharmaceutics 11: S1-S6.

Yang Q, Nanayakkara GK, Drummer C, Sun Y, Johnson C, Cueto R, Fu H, Shao Y, Wang L, Yang WY, Tang P, Liu LW, Ge S, Zhou XD, Khan M, Wang H, Yang X (2017) Low-intensity ultrasound- induced anti-inflammatory effects are mediated by several new mechanisms including gene induction, immunosuppressor cell promotion, and enhancement of exosome biogenesis and docking. Front Physiol 8: 818. DOI: 10.3389/fphys.2017.00818.

Zacherl M, Gruber G, Radl R, Rehak PH, Windhager R (2009) No midterm benefit from low intensity pulsed ultrasound after chevron osteotomy for hallux valgus. Ultrasound Med Biol 35: 1290-1297.

Zara JN, Siu RK, Zhang X, Shen J, Ngo R, Lee M, Li W, Chiang M, Chung J, Kwak J, Wu BM, Ting K, Soo C (2011) High doses of bone morphogenetic protein 2 induce structurally abnormal bone and inflammation in vivo. Tissue Eng Part A 17: 1389-1399.

Zhang ZC, Yang YL, Li B, Hu XC, Xu S, Wang F, Li M, Zhou XY, Wei XZ (2019) Low-intensity pulsed ultrasound promotes spinal fusion by regulating macrophage polarization. Biomed Pharmacother 120: 109499. DOI: 10.1016/j.biopha.2019.109499.

Zhao X LS, Yildirimer L, Zhao H, Ding R, Wang H, Cui W, Weitz D (2016) Injectable stem cell-laden photocrosslinkable microspheres fabricated using microfluidics for rapid generation of osteogenic tissue constructs. Adv Funct Mater 26: 2809-2819.

Zura R, Della Rocca GJ, Mehta S, Harrison A, Brodie C, Jones J, Steen RG (2015a) Treatment of chronic ( $>1$ year) fracture nonunion: heal rate in a cohort of 767 patients treated with low-intensity pulsed ultrasound (LIPUS). Injury 46: 2036-2041.

Zura R, Mehta S, Della Rocca GJ, Jones J, Steen RG (2015b) A cohort study of 4,190 patients treated with low-intensity pulsed ultrasound (LIPUS): findings in the elderly versus all patients. BMC Musculoskelet Disord 16: 45. DOI: 10.1186/s12891-015-0498-1.

Zura R, Xiong Z, Einhorn T, Watson JT, Ostrum RF, Prayson MJ, Della Rocca GJ, Mehta S, McKinley T, Wang Z, Steen RG (2016) Epidemiology of fracture nonunion in 18 human bones. JAMA Surg 151: e162775. DOI: 10.1001/jamasurg.2016.2775.

Zura R, Xu ZK, Della Rocca GJ, Mehta S, Steen RG (2017) When is a fracture not "fresh"? Aligning reimbursement with patient outcome after treatment with low-intensity pulsed ultrasound. J Orthop Trauma 31: 248-251.

\section{Discussion with Reviewers}

Reviewer 1: Do you think an advanced design of an in vitro set-up might improve the comparability of the LIPUS stimulation? Would a "tissue-mimicking" in vitro approach be an option?

Authors: Due to the complexity of physical phenomena induced by LIPUS, which are highly dependent on the structural and material properties of the interrogated material, the physical sub-mechanisms differ in vivo vs. in vitro. A better understanding of which submechanisms are encountered in the clinical setting and their proper translation into advanced in vitro and in vivo set-ups, supported by in silico studies can indeed help to decipher the resulting biological 
phenomena. Most of the existing in vitro set-ups do not allow for controlled transfer of the acoustic dose and, furthermore, introduce physical artefacts, as discussed by Padilla et al. (2014). This produces misleading results that most likely do not reflect the clinical reality. Creating tissue constructs, mimicking as closely as possible the material properties of bone and other surrounding tissues could be an excellent way to study the physico-biological mechanisms of ultrasound stimulation and could be object of future research. This research could yield a re-optimisation of the LIPUS acoustic parameters originated from a rabbit animal model (Duarte, 1983). Such studies should be performed using advanced in vitro and in vivo set-ups.

Reviewer 1: Based on all the information given in the present review, LIPUS might be effective but a good clinical trial is still missing. What could be the main reasons why a well-designed trial was not conducted even through LIPUS has been used since the early 1990s?

Authors: We do not have a clear explanation on why a well-designed trial has not yet been conducted. We can only speculate that clinical trials with nonunions, for example, are unlikely to include LIPUS as a first-line treatment. Patients might be referred to it only after the failure of other type of treatments (e.g. surgery). However, for more "simple" fracture types, we believe that the hurdles in conducting such trails might be more related to the difficulty of finding a funding source, especially if companies are not willing to sponsor them. We can only speculate that LIPUS-device manufacturers, principally Bioventus, who sells the Exogen ${ }^{\circledR}$ system, do not see the need of sponsoring further a long and costly clinical trial to improve acceptance and/or rentability of their operations. The device is already approved by several regulatory agencies worldwide and it seems to be commercially successful. Additionally, providersponsored trials raise questions of bias, diminishing the concluded findings. We purposely decided not to contact manufacturers on this issue to remain neutral and propose an objective review of published data.

Reviewer 2: What is/are the main future research direction(s) of LIPUS on bone regeneration?

Authors: A thorough characterisation of acoustic dose in preclinical models, followed by its translation to human is an important first step towards the reproducibility and acceptance of the LIPUS therapy. This dose should be further optimised for "special conditions", such as bones with impaired healing, elderly individuals and patients with underlying health conditions. The defined parameters should be tested in preclinical models and verified in wellcontrolled clinical studies.

LIPUS has been also shown to have synergistic effects in vitro and in vivo, when used together with other therapies, e.g. growth factors such as BMP-2 (Angle et al., 2014, additional reference) and BMP-7
(Koga et al., 2013; Lee et al., 2013, additional reference) and mesenchymal stromal cells (Carina et al., 2017; Chen et al., 2019; Polo-Corrales et al., 2018, additional references), enhancing effects of those treatments. This could be another direction towards exploration of the LIPUS capabilities for tissue regeneration.

Reviewer 2: Is LIPUS scientifically sound for clinical application for bone regeneration?

Authors: There is no doubt that stimulation with LIPUS induces pro-regenerative processes in biological tissues, such as bone, and that this therapy has potential to be used for clinical treatment of bone fractures. However, at this point, randomised doubleblind clinical trials with defined and characterised acoustic doses, enrolling large patient cohorts and ensuring patients compliance following support of the medical personnel, are necessary to draw definitive conclusions.

Melanie Haffner-Luntzer: What lessons can we learn from animal models regarding LIPUS application during fracture healing and what might be the limitations?

Authors: Preclinical models are crucial for evaluation of a therapy's efficacy, determination of the underlying mechanisms and optimisation of conditions for its improvement. The use of LIPUS in small animal models, such as rats and rabbits, has shown profound pro-regenerative effects in bone fractures at various locations. However, translation of those findings to the clinical setting, unfortunately, has not always been found successful. One of the biggest limitations to translate preclinical results to the clinical setting could be the fact that the same probes and stimulation parameters were used in most of the preclinical and in the clinical studies, although animal and human proportions, including the soft tissue amount or the bone defect size, differ greatly. This brings us to the question of whether the LIPUS acoustic parameters are directly translatable from preclinical models to patients, or if there is a so-called "acoustic dose" that is suitable for a small animal and which should be then appropriately scaled for a human. Depending on type of fracture, fracture location, patients' characteristics and their medical history, this acoustic dose needs to be standardised and further tested in preclinical models and clinical studies.

\section{Additional References}

Angle SR, Sena K, Sumner DR, Virkus WW, Virdi AS (2014) Combined use of low-intensity pulsed ultrasound and rhBMP-2 to enhance bone formation in a rat model of critical size defect. J Orthop Trauma 28: 605-611.

Carina V, Costa V, Raimondi L, Pagani S, Sartori M, Figallo E, Setti S, Alessandro R, Fini M, Giavaresi G (2017) Effect of low-intensity pulsed ultrasound on osteogenic human mesenchymal stem cells 
commitment in a new bone scaffold. J Appl Biomater Funct Mater 27: e215-e222.

Chen C, Zhang T, Liu F, Qu J, Chen Y, Fan S, Chen H, Sun L, Zhao C, Hu J, Lu H (2019) Effect of low-intensity pulsed ultrasound after autologous adipose-derived stromal cell transplantation for bone-tendon healing in a rabbit model. Am J Sports Med 47: 942-953

Lee SY, Koh A, Niikura T, Oe K, Koga T, Dogaki Y, Kurosaka M (2013) Low-intensity pulsed ultrasound enhances BMP-7-induced osteogenic differentiation of human fracture hematoma-derived progenitor cells in vitro. J Orthop Trauma 27: 29-33.

Polo-Corrales L, Ramirez-Vick J, Feria-Diaz JJ (2018) Recent advances in biophysical stimulation of MSC for bone regeneration. Indian J Science Technology 11: 1-41.

Editor's note: The Guest Editor responsible for this paper was Anita Ignatius. 